Discussion Paper No. 805

\title{
IMPACTS OF FORCED MARRIAGES \\ IN CAMBODIA \\ UNDER THE POL POT REGIME
}

\author{
Katsuo Kogure \\ The $13^{\text {th }}$ ISER-Moriguchi Prize (2010) \\ Awarded Paper
}

March 2011

The Institute of Social and Economic Research

Osaka University

6-1 Mihogaoka, Ibaraki, Osaka 567-0047, Japan 


\title{
Impacts of Forced Marriages in Cambodia under the Pol Pot Regime*
}

\author{
Katsuo Kogure ${ }^{\dagger}$ \\ University of Tsukuba
}

February 2011

\begin{abstract}
This paper investigates effects of forced marriages in the Pol Pot regime on educational investments for their children. Specifically, we focus on the difference in educational investments between the couples who faced different social environments under the Pol Pot regime. Using the complete set of retrospective census microdata, we estimate the average treatment effects on the treated with inverse probability weighting estimation. Our estimation results suggest that forced marriages had negative impacts on child education. In particular, a harsher social environment had larger negative impacts on child education.
\end{abstract}

JEL Classifications: N45, O43, P36.

Keywords: child education, forced marriage, the Pol Pot regime.

*I am grateful to my main advisor Atsushi Yoshida for his valuable guidance, comments and support throughout this project. I am also grateful to my advisors Yoko Kijima and Ryo Nakajima for their valuable guidance and comments at various stages. I am also grateful to Niu Bing, Mamoru Kaneko and Koichi Ushijima for many valuable discussions. I am also grateful to Tomoki Fujii, Hidehiko Ichimura, Hisahiro Naito, Yoshito Takasaki and seminar participants at Hitotsubashi University, Kanazawa University, Nihon University, Osaka University, University of Tsukuba, University of Tokyo, and Kansai Labor Workshop for helpful comments and suggestions. Special thanks also go to H.E. San Sy Than and Hang Lina for providing and assisting with 1998 Census microdata. The paper does not reflect the views of the National Institute of Statistics, Ministry of Planning, Cambodia. The previous version of this paper was awarded the 13th Moriguchi Prize by the Institute of Social and Economic Research (ISER) at Osaka University.

${ }^{\dagger}$ Graduate School of Systems and Information Engineering, University of Tsukuba, 1-1-1 Tennodai, Tsukuba, Ibaraki 305-8573, JAPAN. Email: kkogure@sk.tsukuba.ac.jp 


\section{Introduction}

We conduct an econometric study of effects of forced marriages in the Pol Pot regime on child education after its collapse. The Pol Pot regime ruled Cambodia from 1975 to 1979 in a form of primitive communism and affected severely all the citizens in their socio-economic and cultural lives. The Pol Pot regime totally destroyed the former politico-socio-economic systems and forced all the citizens to change into their lives following the new system until January 1979. We are interested in effects of the Pol Pot regime on general socio-economic behavior. In this paper, we in particular choose the forced marriage system employed in the regime and estimate its effects on child education afterward. In this introduction, we first give a brief summary of historical background relevant for our study. We then explain our econometric study and finally consider implications derived from our results.

Forced marriages were broadly implemented in Cambodia under the Pol Pot regime (e.g. Dy 2007). The forced marriage system was quite different from conventional marriage system. While parents traditionally choose a marriage partner for their son or daughter, they, in most cases, were not allowed to be involved in any decision under the new system. Instead, marriage was designated by "Angkar" which claimed to be everyone's mother and father, and each couple could not refuse the order from Angkar. ${ }^{1}$ Nevertheless, no statistical data about forced marriages are available.

Our evaluation approach is to investigate the differences in socio-economic behavior between the households formed under the Pol Pot regime and those formed after the Pol Pot regime. We then examine the possible effects of the forced marriage system on socio-economic behavior.

In this evaluation, we focus on the difference in educational investments between the couples from urban areas and those from rural areas. Under the Pol Pot regime, they were called new and base people and faced very different social environments. Urban people (new people) were regarded as enemies of society and were persecuted by the Khmer Rouge. They were forced to migrate from urban to rural areas and were given no political rights. Many of them were victimized into genocide. On the other hand, rural people (base people) were regarded as innocent and given the privileged rights to build a nation.

We also examine the differences in the effects of the forced marriage system on socioeconomic behavior among different regions. During the Pol Pot regime, different leaders were assigned from the central committee, and ruled each administrative zone. Historical documents report that the degree of harshness was different in each zone. For example, people in Southwest zone were treated severely, while those in East zone were treated less

\footnotetext{
${ }^{1}$ Angkar, which literally means organization, did not exist in reality. However, people were instructed to believe, obey and respect Angkar.
} 
harshly (e.g. Kiernan 1996).

The evaluation method that we employ is the econometric method of program evaluation based on the potential outcomes framework (e.g. Rubin 1974; Holland 1986). The parameter that we are interested in is the average treatment effects on the treated (ATT). This parameter addresses the question of what households formed under the Pol Pot regime would experience had they be formed after the Pol Pot regime. Using the complete set of retrospective 1998 census microdata, we employ the inverse probability weighting (IPW) estimation to identify the ATT parameter. In the first step, we estimate logit models by maximum likelihood estimation and obtain the estimated propensity scores. In the second step, we conduct weighted least squares estimation using these propensity scores as weights.

Our estimation results show the differences in educational investment between the households formed under the Pol Pot regime and those formed after the Pol Pot regime. We find the investment in child education was lower for the households formed under the Pol Pot regime than for those formed after the Pol Pot regime. This finding suggests that forced marriages in the Pol Pot regime had negative impacts on child education after its collapse.

Our estimation results also reveal the differences between new and base people. While the investment in child education was lower for the households formed under the Pol Pot regime than for those formed after the Pol Pot regime for both new and base people, much larger effects are found for the new people.

Our estimation results also show the differences among different administrative zones under the Pol Pot regime. We find that the investment in child education was lower for the households in West, Central, and in particular Southwest zone formed under the Pol Pot regime than for those formed after the Pol Pot regime in these zones. On the other hand, less difference can be seen in Northwest, East, and North zone.

These findings suggest that the differences in social environments under the Pol Pot regime led to different impacts on child education. During the Pol Pot regime, new and base people were treated differently. In particular, new people were persecuted. Historical documents report the degree of differences in control among different administrative zones. For example, Southwest zone was a special zone during the Pol Pot regime and people in Southwest zone were harshly controlled by the Khmer Rouge (e.g. Kiernan 1996; Vannak 2003). The Khmer Rouge in East zone was less brutal than those in other zones (e.g. Kiernan 1996). The estimation results with these historical evidences then suggest that a harsher social environment had more negative impacts on child education.

Our results provide the implication that a rule with strong political power such as 
dictatorship may trigger the emergence of difference in culture. In this case, social environments may play an important role in creating cultural differences, which may be persistent and have different effects on socio-economic behavior.

The remainder of the paper is structured as follows. Section 2 provides historical background. Section 3 explains data and development of samples. Section 4 describes the characteristics of the samples with descriptive statistics and graphs. Section 5 presents econometric method. Section 6 provides estimation results. Section 7 provides the interpretations of our findings. Section 8 concludes.

\section{Historical Background and Data}

\subsection{Historical Background}

The Communist Party of Kampuchea, which is well known as the Khmer Rouge, led by Pol Pot won the civil war against the Khmer Republic regime led by Marshal Lon Nol on 17th in April, 1975. The Khmer Rouge then established the state of the Democratic Kampuchea in 1976 and governed the country with strong political power until 7th in January, 1979. In this section, we first explain how the Khmer Rouge gained political power during the Vietnam War. We then describe social experiments implemented under the Khmer Rouge regime and finally introduce the marriage system under the Khmer Rouge regime.

\section{A. Rise of the Khmer Rouge in Cambodia, 1970 - 1975}

Political situation in Cambodia was complex and unstable from 1970 to 1975. Cambodia was gradually influenced by the Vietnam War. During the Vietnam war, Prince Sihanouk permitted North Vietnam to construct the Ho Chi Minh Trail for providing material supplies from North to South, while he had taken a neutral stance for diplomatic policy. Consequently, a relationship with the United States deteriorated.

In March 1970, Marshal Lon Nol and his associates who were pro-United States successfully seized power in a coup when Prince Sihanouk was outside the country. They deposed Prince Sihanouk from head of state and established the Khmer Republic, which was backed by the United States. As a result, the United States invaded into Cambodia to cut the Ho Chi Minh Trail and expanded the campaign of secret bombing in Cambodia.

During this period, the Khmer Rouge gradually gained political power. The Khmer Rouge attracted more people who did not want to support the Lon Nol government and wanted to restore Prince Sihanouk to power. Prince Sihanouk who went into exile in China 
also encouraged people to join the Khmer Rouge to overthrow the Lon Nol government. Consequently, the number of Khmer Rouge soldiers increased from about 3,000 in 1970 to over 40,000 in 1973 and about 85 percent of Cambodian territory was in hands of the Khmer Rouge by early 1973. Finally, the Khmer Rouge won the five-year civil war against the Lon Nol government on 17th in April, 1975 (cf., Dy 2007).

\section{B. Social Revolution under the Khmer Rouge Regime, 1975 - 1979}

The Khmer Rouge established the state of the Democratic Kampuchea in 1976 and governed the country with strong political power until 7th in January, 1979. During this period, the Khmer Rouge implemented the radical institutional changes which were influenced by primitive communism of Mao Zedong, Marx and Lenin. The forced marriage system studied in this paper is one of them. Examples of social revolution are forced migration, forced labor, genocides, and abolition of private property rights, market function, normal schooling, religious practice, traditional Khmer culture.

The Khmer Rouge classified people into the two groups: base and new people. The base people who spent their whole lives in rural area before the Pol Pot regime were regarded as innocent to the regime. ${ }^{2}$ Under the regime, they were given the privileged rights to play a role in accomplishing the revolution. On the other hand, the new people who were from urban area were regarded as enemies of new society and were persecuted under the regime. They were given no political rights and their political powers were completely reduced during the Pol Pot regime. Many intellectual citizens in this group were victimized to genocide. ${ }^{3}$

The Khmer Rouge divided the country into six geographical zones to manage the country effectively. The Khmer Rouge leaders were assigned to each administrative zone and implemented social revolution following orders from the central committee. The details about administrative zones in the regime were presented in Appendix.

The Khmer Rouge regime did not give political power to Prince Sihanouk. To secure political power, the Khmer Rouge invited Prince Sihanouk who was in North Korea to come back to Cambodia in July 1975 and forced him to resign as head of states. This resulted in the end of nearly two thousand year lasting monarchy system in Cambodia. The Khmer Rouge then kept Prince Sihanouk isolated in the Royal Palace in Phnom Penh not to allow him to leave the country just before the collapse of the Khmer Rouge regime.

\footnotetext{
${ }^{2}$ Rural people who were evacuees during the civil war were regarded as new people in the Pol Pot era. Most of them were not allow to go back to their homeland during the regime. They are not included in the samples of this study.

${ }^{3}$ See e.g. Kiernan (1996)
} 


\section{Marriage under the Khmer Rouge Regime, 1975 - 1979}

Marriage under the Khmer Rouge regime was different from traditional one. Although parents traditionally choose a marriage partner for their son or daughter, they, in most cases, were not allowed to involve in any decision-making under the new system. Instead, Angkar which was everyone's mother and father decided marriage partners. People were not allowed to refuse the order from Angkar to get married. In an extreme case, their refusal could have resulted in punishment or death. A role of marriage under the regime was not to form family units, but to produce pure children who could serve the revolution of the new regime.

\subsection{Data}

We employ the complete set of microdata from General Population Census of Cambodia in 1998. We focus on child education for a first child and children aged 6-14 as household outcomes. Because of our sampling design, which is discussed in the next section, we separately develop outcome measures for these two groups. Outcome measures for a first child are (1) an indicator variable for graduating from primary school and (2) an indicator variable for having never attended school, while those for children aged 6-14 are (3) an indicator variable for attending school at the time of census period and (4) an indicator variable for having never attended school. The detailed definitions of variables used in this paper are presented in appendix.

\section{Development of Samples}

\subsection{Treatment and Control Households}

While census data contain the information on basic demographic and socio-economic characteristics of households and individuals, they do not include the information on when households were formed. Consequently, we can never observe which households were formed under the Pol Pot regime. Instead, we specify a part of the households which were highly likely to be formed under the Pol Pot regime by focusing on mother's age and the time of having a first child.

We illustrate this with Table 1. Panel (A) shows the age table for children aged 15-21, while that for women aged 33-39 is presented in Panel (B). The tables contain the ages of these people at each year from 1971-83. Our target population is the households with mother aged 34-38 and a first child aged 19-20 as of 1998. We assume they were formed 
under the Pol Pot regime. Recall that the Pol Pot regime started in April 1975 and ended in January 1979. Mother aged 34-38 were 11-15 years old in 1975. They appear to be too young to get married before the Pol Pot regime. If they gave a birth to a first child in 1978-1979, they were highly likely to get married under the Pol Pot regime. We call a set of these households a treatment group. We then divide the treatment group into two groups based on the time of having a first child. We call a group of the households with a first child aged 20 "Treatment 1" and that with a first child aged 19 "Treatment 2".

We next specify control households in the same way by focusing on mother's age and the time of having a first child. We select the households with mother aged 34-38 and a first child aged 16-17 as control households. We assume they were formed after the Pol Pot regime. We don't employ the households with a first child aged 18 as control households, because some of them might be formed under the Pol Pot regime. We develop two control groups based on the time of having a first child. We call a group of the households with a first child aged 17 "Control 1" and that with a first child aged 16 "Control 2". ${ }^{4}$ Using these two control samples, we evaluate Treatment 1 and Treatment 2.

\subsection{Definition of Base and New People}

We classify households into base and new people based on mother's status during the Pol Pot regime. A household is defined as base people if mother's birth place is neither a provincial town nor Phnom Penh and the birth place of a first child is same as that of mother. On the other hand, a household is defined as new people if mother's birth place is a provincial town or Phnom Penh.

\subsection{Sampling}

Using the complete set of census microdata, we implement a sampling to develop both treatment and control groups. The detailed procedures are summarized in Table 2. There are 2,188,177 households in census data. First, we restrict the households with a first child aged 16, 17, 19, and 20, which results in 351,071 households. We then impose ten conditions to reduce unobservable factors affecting outcomes. This is shown in (2) through (11). Next two conditions address limitations of census data. One limitation is that they do not collect the information on when households were formed. As a result, remarried households formed after the Pol Pot regime might be included in the treatment groups. Condition (12) is imposed to reduce those households from our samples. Another

\footnotetext{
${ }^{4}$ There is still concern that the households formed under the Pol Pot might be included in the control households. To address this, we prepare for two different control groups and obtain reliable estimates.
} 
limitation is that census data do not contain the information of the household members who lived elsewhere at the time of census. This might happen when children had got married and formed a new independent household. This threatens the validity of our indicator to identify a first child in a household. Condition (13) is imposed to make it a right indicator of a first child. We obtain two treatment and control groups. The number of households in Treatment 1 and 2 are 1,230 and 3,993, while those in Control 1 and 2 are 14,661 and 15,761. We finally develop nine samples with different combinations of treatment and control groups for our evaluation.

\subsection{Attrition Problem}

There is concerned about attrition problem for the samples developed in the previous section. Because women who were forced to marry under the Pol Pot regime were no longer to stay together after the collapse of the regime, they may be more likely to divorce as of 1998. To explore this, the proportions of mother's marital status by different groups and samples are presented in Table 3. The proportion of mother's marital status for base people is shown in panel (A), while that for new people is provided in panel (B). Although the proportion of married households is 86.4 percent for new people in Treatment 1 , that for the rest of the samples exceed 90 percent. This suggests that most of the households still stay together after it took about 20 years since the Pol Pot regime ended in 1979. 5 Because attrition problem is not serious, we use only "married" households for our evaluation.

\section{Characteristics of the Samples}

In this section, we describe the characteristics of the samples. First, we present the descriptive statistics of the samples. Second, we provide graphical analyses on outcomes. Finally, we show the ArcGIS maps on spatial distributions of the samples.

\subsection{Descriptive Statistics}

Table 4 provides the descriptive statistics by different groups and samples. The table consists of the three panels: (A) Household Characteristics, (B) Characteristics of A First Child, and (C) Characteristics of Children Aged 6-14.

\footnotetext{
${ }^{5}$ One possible reason is that sex imbalance due to the Pol Pot regime gives less incentive for women to divorce.
} 
Households. Panel (A) provides the means and standard deviations about household characteristics. Descriptive statistics for base people are shown in column (1) and (2) for treatment groups and in column (3) and (4) for control groups. Treatment 1 contains more female headed households than other three groups. Mother's age is similar between treatment and control groups. There are slightly differences in father's age, mother's education, and father's education between treatment and control groups. Father's age, mother's education, and father's education are larger for treatment groups than for control groups. The proportion of whether father is new people is similar between treatment and control groups.

Descriptive statistics for new people are shown in column (5) and (6) for treatment groups and in column (7) and (8) for control groups. Treatment groups contain more female headed households than control groups. There are also differences between treatment groups. The proportion of female headed households is larger for Treatment 1 than for Treatment 2. Mother's age is similar between treatment and control groups. Father's age is larger for treatment groups than for control groups. There are differences in mother's education, father's education, and father's class is new between treatment 1 and other three groups. Mother's and father's education are lower for Treatment 1 than for Treatment 2 and control groups. The proportion of whether father is new people is larger for Treatment 1 than for Treatment 2 and control groups.

A First Child. Panel (B) presents the means and standard deviations about the characteristics of a first child. Descriptive statistics for a first child of base people are shown in column (1) and (2) for treatment groups and in column (3) and (4) for control groups. There are no variations in age of a first child for each group due to our sampling design. The proportion of female is smaller for treatment groups than for control groups. The table also shows the difference in outcomes between Treatment 1 and other three groups. The first child in Treatment 1 is less likely to graduate from primary school than that in other three groups. In addition, the proportion of a first child who has never attended school is larger for Treatment 1 than for Treatment 2 and control groups.

Descriptive statistics for a first child of new people are shown in column (5) and (6) for treatment groups and in column (7) and (8) for control groups. The proportion of female is smaller for treatment groups than for control groups. The proportion of a first child who graduated from primary school is smaller for Treatment 1 than for Treatment 2 and two control groups. The proportion of a first child who has never attended school is larger for Treatment 1 than for Treatment 2 and control groups. While these findings are similar to those for a first child of base people, it is found that there are much larger differences in educational investments for a first child of new people between Treatment 
1 and two control groups. The descriptive statistics on outcomes in panel (B) show that there are differences in educational investment for a first child between Treatment 1 and control groups, but not between Treatment 2 and two control groups. While this can be seen for both base and new people, larger differences are found for new people.

Children aged 6-14. Panel (C) presents the means and standard deviations about the characteristics of children aged 6-14. Descriptive statistics for children of base people are shown in column (1) and (2) for treatment groups and in column (3) and (4) for control groups. Average of child age and proportion of female is close between treatment and control groups. The table shows the difference in outcomes between Treatment 1 and other three groups. The proportion of children currently attending school is smaller for Treatment 1 than for Treatment 2 and two control groups. In addition, the proportion of children who have never attended school is larger for Treatment 1 than for other three groups. These findings are consistent with those for a first child.

Descriptive statistics for children aged 6-14 of new people are shown in column (5) and (6) for treatment groups and in column (7) and (8) for control groups. There are not clear differences in average of child age and proportion of female between treatment and control groups. There are differences in educational outcomes between treatment and control groups. The proportion of children aged 6-14 who are currently attending school is smaller for treatment groups, in particular for Treatment 1, than for control groups. In addition, the proportion of children aged 6-14 who have never attended school is larger for treatment groups, particularly for Treatment 1, than for control groups. The descriptive statistics on outcomes in panel $(\mathrm{C})$ show that there are differences in educational investment for children aged 6-14 between Treatment 1 and control groups, but not between Treatment 2 and control groups for base people. On the other hand, they also show that an educational investment for children aged 6-14 of new people is lower for treatment groups, in particular for Treatment 1, than for control groups.

\subsection{Graphical Analysis}

Figure 1 provides educational attainments of children by different groups. We provide three types of figures that show the differences in child education between treatment and control groups.

Educational Attainment of a First Child. Figure (1a-1) and (1b-1) provide the distributions of educational attainment of a first child for base and new people, respectively. It is found that there are slightly differences in the locations of distributions between treatment and control groups, which suggests that there are difference in educational investment for a first child between these two groups. Educational attainment of a first 
child is lower for treatment groups, in particular for Treatment 1, than for control groups. This is found for both base and new people. On the other hand, there are differences in educational attainment of a first child between Control 1 and Control 2.

Educational Attainment of Children Aged 6-14. Figure (1a-2) and (1b-2) plot the estimated proportions of children aged 6-14 who are currently attending school by different samples and groups. They are constructed using Epanechnikov kernel function to nonparametrically regress the indicator variable of currently attending school or not on the child age variable. Both figures show that there are differences in educational investment between treatment and control groups. The proportion of children who are currently attending school is smaller for treatment groups, in particular for Treatment 1 , than for control groups. While this can be seen for both base and new people, larger difference is found for new people. While we find a difference in educational attainments of a first child between control groups, there is no difference in those of children aged 6-14 between these two groups.

Figure (1a-3) and (1b-3) plot the estimated proportion of children aged 6-14 who have never attended school by different samples and groups. They are developed by employing the same methods mentioned above. Both figures show that the proportion of children who have never attended school is larger for treatment groups, particularly for Treatment 1, than for control groups. In particular, larger difference is found for new people.

\subsection{Spatial Distributions of the Samples}

Figure 2 and 3 provide the spatial distributions of the households for base and new people, respectively. There are two objectives to plot the samples onto maps. One objective is to grasp how the samples are spatially distributed within a country. Another objective is to check whether the geographical distributions of control samples are well overlapped with those of treatment samples. This is important in developing counter factual outcomes for treatment groups. ${ }^{6}$

Figure 2 and 3 show that the samples of base people are widely distributed throughout the country, while those of new people are distributed in limited areas. They also show that the geographical distributions of control samples are well matched with those of treatment samples for both base and new people.

\footnotetext{
${ }^{6}$ In program evaluation literature on job training programme, geographical mismatch between treatment and control groups is major source of bias (Heckman, Ichimura and Todd 1997, Heckman, Ichimura, Smith and Todd 1998). Geographical match between treatment and control groups are also important in our context, because educational environments are different among regions.
} 


\section{Econometric Evaluation}

The evaluation method that we employ is an econometric method of program evaluation based on the potential outcomes framework (e.g. Rubin 1974; Holland 1986). In this section, we first define a parameter and then discuss the econometric method as well as the assumptions employed for identification.

\subsection{Parameter of Interest and Assumptions}

The parameter that we are interested in is the average treatment effects on the treated (ATT), which addresses the question of what households formed under the Pol Pot regime would experience had they got married under the conventional marriage system. Despite much attention and concern for a long time, it is still unknown how the Pol Pot regime has affected the well-beings of survivors after the collapse of the regime. ${ }^{7}$ Thus, the ATT parameter is the most appropriate parameter in our context.

We define the ATT parameter as follows. Let $\left(Y_{j}(1), Y_{j}(0)\right)$ denote the potential outcomes of household $j$ with and without treatment, where treatment means that household $j$ was formed under the Pol Pot regime. Let $D_{j}=1$ if household $j$ was formed under the Pol Pot regime and let $X_{j}$ denote a vector of conditioning variables of household $j$. The ATT for our target population is defined as

$$
E\left[Y_{j}(1)-Y_{j}(0) \mid X_{j}, D_{j}=1\right]
$$

Because we focus on child education as household outcomes, we suppose that $X_{j}$ can be divided into two components, $X_{j}=\left(T_{i j}, Z_{j}\right)$, where $T_{i j}$ determines outcomes of child $i$ in household $j$ and $Z_{j}$ influence the treatment status for the households formed under the Pol Pot regime. The ATT in (1) is then redefined as

$$
E\left[Y_{i j}(1)-Y_{i j}(0) \mid T_{i j}, Z_{j}, D_{j}=1\right]
$$

To identify the ATT parameter, we make three key assumptions. The first is conditional independence assumption, which is first introduced by Rosenbaum and Rubin (1983),

\section{Assumption 5.1 (Conditional Independence Assumption)}

$$
Y_{i j}(0) \perp D_{j} \mid T_{i j}, Z_{j}
$$

\footnotetext{
${ }^{7}$ There are scientific evidences in the field of psychiatry that Cambodian survivors suffers from long term post-traumatic stress disorder (PTSD) after the collapse of the Pol Pot regime, suggesting that the Pol Pot regime might have negative effects on their economic outcomes (e.g. Mollica et al. 1993, Mollica et al. 2002, Marshall et al. 2005).
} 
This assumption can be formally written as

$$
\begin{aligned}
\operatorname{Pr}\left(D_{j} \mid Y_{i j}(0), T_{i j}, Z_{j}\right) & =\operatorname{Pr}\left(D_{j} \mid T_{i j}, Z_{j}\right) \\
& =\operatorname{Pr}\left(D_{j} \mid Z_{j}\right)
\end{aligned}
$$

We next make the second assumption about the joint distribution of the treatment and covariates:

\section{Assumption 5.2 (Overlap)}

$$
\operatorname{Pr}\left(D_{j}=1 \mid Z_{j}\right)<1 \quad \text { for all } p_{j} \in \operatorname{supp}\left(P_{j}\left(Z_{j}\right)\right) .
$$

Let $z_{1 j}$ denote an indicator of household $j$ for having a first child. To make it possible to compare between the households with a first child born under the Pol Pot regime and those born after the regime, we assume that the following exclusion restriction is hold:

\section{Assumption 5.3 (Exclusion Restriction)}

$$
Y\left(D_{j}, z_{1 j}\right)=Y\left(D_{j}, z_{1 j}\right) \text { for } D_{j}=0,1 \text { and } z_{1 j}=1 .
$$

\subsection{Estimation Method}

We employ inverse probability weighting (IPW) estimation to estimate the ATT parameter. This method combines propensity score estimation and regression adjustment with weighting. Specifically, we first estimate logit models by maximum likelihood estimation:

$$
\operatorname{Pr}\left(D_{j}=1 \mid Z_{j}\right)=\frac{\exp \left(Z_{j}^{\prime} \gamma\right)}{1+\exp \left(Z_{j}^{\prime} \gamma\right)}
$$

We then estimate weighted least squares models using the propensity scores obtained in the first step as weights:

$$
Y_{i j}=\beta_{0}+\tau_{A T T} \cdot D_{j}+\beta_{1}^{\prime} T_{i j}+\beta_{2}^{\prime}\left(T_{i j}-\bar{T}_{1}\right) \cdot D_{j}+\epsilon_{i j}
$$

where weights are

$$
\lambda_{i j}= \begin{cases}1 & \text { if } D_{j}=1, \\ \frac{\hat{p}\left(Z_{j}\right)}{1-\hat{p}\left(Z_{j}\right)} & \text { if } D_{j}=0,\end{cases}
$$

and $\bar{T}_{1}$ is the sample average of $T$ for the subsample of treated households. ${ }^{8}$

IPW estimation is appropriate in our context. Our samples are not randomly assigned between treatment and control groups. To address this, we use the estimated propensity scores which are obtained in the first step to compare the households with similar

\footnotetext{
${ }^{8}$ See Hirano and Imbens (2001).
} 
characteristics between treatment and control groups. We also need adjustment between children with different characteristics. Despite the unit of our study is a household, we focus on child education as household outcomes. Weighted least square regression in the second step then makes it possible to control for covariates of children. ${ }^{9}$

This method is called "double robust estimation", which is discussed by Robins and Rotnitzky (1995), Scharfstein, Rotnitzky and Robins (1999) and Wooldridge (2007). ${ }^{10}$ In our context, our missspecification for propensity score estimation does not affect the consistency of the ATT parameters in the second step, as long as weighted least squares models are correctly specified. Busso, DiNardo and McCrary (2009) provide the detailed discussion about the relationship between matching and double robust estimation.

\section{Estimation Results}

In this section, we report estimation results. We first present the results of propensity score estimations. We then provide the estimation results of weighted least squares models for base and new people. We finally show the heterogeneous results among base people in different administrative zones.

\subsection{Results of Propensity Score}

Table 5 provides the estimation results of logit models for base people. Parent's characteristics and indicator variables for each administrative zone during the Pol Pot regime are used as covariates. These variables are important factors affecting the status of whether households were formed under the Pol Pot regime, because a way of implementing the forced marriage system might be different among administrative zones. The estimation results show that the households in treatment groups are more likely to contain older mother and father. The coefficients of parent's education and dummies for administrative zones, such as West, Southwest, East, Central, and North zone, are statistically significant in some samples.

Table 6 provides the estimation results of logit models for new people. The estimation results show that the households in treatment groups are more likely to contain older

\footnotetext{
${ }^{9}$ Our estimation approach is also related to sharp regression discontinuity (SRD) design. Our sample construction exploits the discontinuity in political institutions or distribution of political power. However, unlike a standard SRD design, the assignment mechanism is not random even close at the discontinuity point. The ATT parameter of our weighted least squares estimation can be interpreted as the SRD estimand which addresses selection problem with matching.

${ }^{10}$ This estimation approach is often used in the epidemiology literature (e.g. Lunceford and Davidian 2004; Austin and Mamdani 2006).
} 
mother and father. The coefficients of dummies for administrative zones, including West, Southwest, North zone, and Kratie, are statistically significant in some samples. The estimated propensity scores are then used as weights in the second step.

Figure 4 and 5 provide the distributions of estimated propensity score by different samples and groups. While the shapes of distributions between treatment and control groups are different in most of the samples, the distributions of propensity scores for control samples are well overlapped to those for treatment groups in each sample, which suggests there is adequate support between treatment and control samples. We use a 5 percent trimming rule to secure the overlaps between treatment and control groups. ${ }^{11}$

\subsection{Estimation Results on Base and New People}

Table 7 reports the results of inverse probability weighting estimation of equation (4) by different samples and groups. The dependent variables for a first child are the indicator variables for graduating from primary school and for having never attended school, while those for children aged 6-14 are the indicator variables for currently attending school and for having never attended school. The control variables employed in these estimations are child age, square of child age, female dummy, dummy for a female headed household, mother's and father's age, mother's and father's education, and regional dummies. Child age and square of child age are only used for children aged 6-14. The propensity scores obtained in equation (3) are used as weights.

Panel (A) provides the estimates for base people. Let us first focus on the results of a first child, which is shown in panel (A-1). Column (1) through (3) report the estimated ATT for a first child of the households in both Treatment 1 and 2 . Recall that the households in Treatment 1 had a first child born in 1978, while those in Treatment 2 had a first child born in 1979. The estimation results show that marriages under the Pol Pot regime lowered the proportion of a first child who has graduated from primary school by 1.8-4.2 percent. On the other hand, they also show that marriages under the Pol Pot regime raised the proportion of a first child who has never attended school by 2.0-2.3 percent.

Panel (A-2) reports the estimated ATT for the children aged 6-14 of the households in Treatment 1 and 2. The results show that marriages under the Pol Pot regime lowered the proportion of children who are currently attending school by 1.4-2.9 percent, while those raised the proportion of children who have never attended school by 1.8-3.2 percent. All the coefficients are statistically different from zero at conventional significance levels.

\footnotetext{
${ }^{11}$ See Heckman et al (1997).
} 
Let us now move on to the results for the children of new people in Treatment 1 and 2 , which is shown in column (1) through (3) in Panel (B). It is found that marriages under the Pol Pot regime had larger negative impacts on child education for new people than that for base people. The estimation results show that marriages under the Pol Pot regime decreased the proportion of attending school by 2.1-4.7 percent, though statistical significance can be seen only for Sample 1-2. They also show that marriages under the regime raised the proportion of having never attended school by 6.0-6.7 percent. The results in panel (B-2) suggest that marriages under the Pol Pot regime had larger negative impacts on child education for new people than that for base people. They decreased the proportion of attending school by 4.7-5.2 percent, while they increased that of having never attending school by 4.8-5.7 percent. All the coefficients are statistically significant.

We evaluate Treatment 1 and 2 separately to see heterogeneous impacts. The results are presented in column (4) through (6) for Treatment 1 and column (7) through (9) for Treatment 2. They reveal that marriage under the Pol Pot regime had larger impacts on child education for Treatment 1 than that for Treatment 2. The estimation results for base people in panel (A-1) show that marriages under the regime lowered the proportion of a first child who has graduated from primary school by 5.5-7.2 percent for Treatment 1 and by 0.6-3.0 percent for Treatment 2. They also show that marriages under the regime raised the proportion of a first child who has never attended school by 5.8-6.4 percent for Treatment 1, while none of the coefficients of ATT parameters for Treatment 2 are statistically significant. The estimation results for children aged 6-14 in panel (A-2) show that the marriage under the Pol Pot regime lowered the school participation rate by 3.34.4 percent for Treatment 1 and by 0.9-2.3 percent for Treatment 2. They also present that marriages under the regime raised the proportion of having never attending school by 3.9-4.9 percent for Treatment 1 and by 1.2-2.6 percent for Treatment 2 .

The estimated ATT are also different between Treatment 1 and 2 for new people. The results in panel (B-1) show that marriages under the Pol Pot regime lowered the proportion of a first child who has graduated from primary school by 7.6-11.9 percent for Treatment 1 , while none of the ATT is statistically significant for Treatment 2. They also show that marriages under the regime raised the proportion of a first child who has never attended school by 13.8-17.2 percent for Treatment 1, while none of the coefficients is statistically significant for Treatment 2. The estimation results for children aged 6-14 in panel (B-2) show that marriages under the Pol Pot regime decreased the school participation rate by 9.7-10.7 percent for Treatment 1 and by 3.8-4.0 percent for Treatment 2. They also show that marriages under the regime increased the proportion of having never attending school by 9.8-11.1 percent for Treatment 1 and by 4.0-4.5 percent for Treatment 2 . 
Overall, the results in Table 7 indicate that marriages under the Pol Pot regime had negative impacts on child education for both base and new people. In particular, much larger effects are found for children of new people.

In the next section, we explore the heterogeneous impacts among different administrative zones under the Khmer Rouge regime. We in particular focus on base people and develop the subsamples for Northwestern, West, Southwest, East, Central, and North zone, respectively. We then estimate the ATT using the same methods employed in this section.

\subsection{Estimation Results Among Different Regions}

We estimate the logit models of equation (3) for each subsample. In doing this, we employ the same covariates used in Table 5, except the dummies for administrative zones. The estimated propensity scores are then used as weights for weighted least square estimation of equation (4). The details results of these estimations are summarized in Appendix. The distributions of estimated propensity scores for each sample are also presented in Appendix.

Table 8 reports the results of inverse probability weighting estimation of equation (4) for six subsamples. The dependent variables for a first child and children aged 6-14 are same as those used in Table 7 . The control variables are also same as those used in Table 7. Column (1) through (3) report the estimated ATT for children of the households in both Treatment 1 and 2. Let us first focus on the results for a first child. The estimation results show that none of the coefficients are statistically significant for Northwest and West zone, suggesting that marriages under the Pol Pot regime had no impacts on child education of the households in these two zones. They also show that most of the estimated ATT are statistically insignificant for East, Central, and North zone, suggesting that marriages under the Pol Pot regime had less impact on education of a first child in these zones. On the other hand, it is found that all the coefficients are statistically significant for Southwest zone, which suggests that marriages under the Pol Pot regime had a negative impact on child education for Southwest zone. Specifically, they lowered the proportion of graduating from primary school by 3.6-8.8 percent and raised that of having never attended school by 5.2-6.7 percent.

Let us now focus on the results for children aged 6-14. The estimation results show that none of estimated ATT is statistically significant for Northwest, East, and North zone, which suggests that marriages under the Pol Pot regime had no impact on child education of the households in these zones. The results also show that most of the estimated ATT are statistically insignificant for West and Central zone, suggesting that marriages under 
the Pol Pot regime had less impact on child education of the households in these zones. On the other hand, statistical significance can be seen in all the coefficients for Southwest zone. The results show that marriage under the Pol Pot regime lowered the proportion of attending school by 8.3-8.6 percent and raised that of having never attending school by 8.8-9.4 percent.

We then evaluate the households in Treatment 1 and Treatment 2 by different administrative zones. The results are presented in column (4) through (6) for Treatment 1 and column (7) through (9) for Treatment 2. Main findings for a first child are as follows. First, marriages under the Pol Pot regime lowered child education for both Treatment 1 and 2 in Southwest zones. In particular, larger effects are found for Treatment 1. For example, marriages under the regime raised the proportion of having never attended school by 9.8-10.9 percent for Treatment 1 , while they raised that by 4.5-5.4 percent for Treatment 2. Second, marriages under the regime lowered child education for Treatment 1, but not for Treatment 2 in West, East, and Central zone. Third, most of the estimated ATT coefficients are statistically insignificant, which suggests that marriages under the Pol Pot regime had no impacts on child education for both Treatment 1 and 2 in Northwest and North zone.

Let us now move on the main results for children aged 6-14 by different administrative zones. It is found that marriages under the regime lowered child education for both Treatment 1 and 2 in Southwest zone. In particular, larger effects are found for Treatment 1. Specifically, marriages under the regime lowered the proportion of attending school by 10.0-10.8 for Treatment 1 and by 7.8-7.9 for Treatment 2, while they raised the proportion of having never attended school by 11.2-11.6 for Treatment 1 and by 8.3-8.5 for Treatment 2. It is also found that marriages under the regime lowered child education of the households in West and Central zone for Treatment 1, but not that for Treatment 2. It is also found that almost all the estimated ATT coefficients are statistically insignificant for both Treatment 1 and 2 in Northwest, East, and North zone. This suggests that marriages under the Pol Pot regime had no impacts on child education for the households in these zones.

Overall, the results in Table 8 indicate that marriages under the Pol Pot regime lowered the educational attainment of children in Southwest zone, while they had negative impacts on child education for Treatment 1, but not for Treatment 2 in West and Central zone. On the other hand, they had less negative impact on child education for both Treatment 1 and 2 in Northwest, East, and North zone. 


\section{$7 \quad$ Interpretation of the Findings}

Our estimation results in Table 7 and 8 provide the following main findings. First, our estimation results have shown the differences in educational investment for children between the households formed under the Pol Pot regime and those formed after the Pol Pot regime. The investment in child education was lower for the households formed under the Pol Pot regime than those formed after the Pol Pot regime. This suggests that forced marriages employed in the Pol Pot regime had negative impacts on child education after its collapse.

Second, our estimation results have also shown the differences between urban and rural people. While the investment in child education was lower for the households formed under the Pol Pot regime than for those formed after the Pol Pot regime for both urban and rural people, much larger difference is found for the urban people.

Third, our estimation results have also shown the differences among different regions. The investment in child education was lower for the households in West, Central, and in particular Southwest zone formed under the Pol Pot regime than for those formed after the Pol Pot regime in each zone. On the other hand, less difference between those households can be seen in Northwest, East, and North zone.

Fourth, our estimation results have also shown the differences between the households with a first child born in 1978 and those in 1979. Larger difference is found for the households with a first child born in 1978. This finding can be seen for both urban and rural people as well as for the base people in different administrative zones.

Our interpretation of these findings is that the differences in culture emerging in the Pol Pot regime led to different impacts on child education. During the Pol Pot regime, urban and rural people were treated differently. In particular, urban people were persecuted during the Pol Pot regime. Historical documents report the degree of differences in control among different administrative zones. For example, Southwest zone was a special zone during the Pol Pot regime and people in Southwest zone were harshly controlled by the Khmer Rouge (e.g. Kiernan 1996; Vannak 2003). The Khmer Rouge in East zone was less brutal than those in other zones (e.g. Kiernan 1996). During the Pol Pot regime, the households with a first child born in 1978 appear to face harsher conditions than those born in 1979, because they spent more time in raising the child under severer circumstance in the Pol Pot regime. The estimation results and these historical evidences then suggest that a harsher social environment had more negative impacts on child education. 


\section{Conclusion}

This paper has analyzed the effects of the forced marriage system employed in the Pol Pot regime on child education. Because no statistical data on forced marriages were available, we have investigated the differences in educational investment for children between the households formed under the Pol Pot regime and those formed after the Pol Pot regime. In particular, we have focused on the differences between urban and rural people and among different regions and provided the empirical evidences suggesting that forced marriages had negative impacts on child education. We have also argued that the culture emerging in the Pol Pot regime had different impacts on child education. In particular, we have pointed out that harsher social environment had more negative impacts on child education.

Because we evaluate a part of the households formed under the Pol Pot regime, careful attention needs to be paid to our interpretations. In addition, because the census data employed in this study do not contain much information on household income, covariates may not be fully adjusted between the household formed under the Pol Pot regime and those formed after the Pol Pot regime.

Although these limitations are placed on, our results provide the implication that a ruling with strong political power such as dictatorship may trigger the emergence of differences in culture. In this case, social environments may play an important role in creating cultural differences, which may be persistent and have different effects on socioeconomic behavior. 


\section{References}

[1] Austin, P.C., and Mamdani, M.M. (2006): "A Comparison of Propensity Score Methods: A Case-Study Estimating the Effectiveness of Post-AMI Stain Use," Statistics in Medicine, 25, 2084-2106.

[2] Busso, M., J. DiNardo, and J. McCrary (2009): "Finite Sample Properties of Semiparametric Estimators of Average Treatment Effects," Working Paper, UC - Berkeley.

[3] Dy, K. (2007): "A History of Democratic Kampuchea (1975 - 1979)", Documentation Center of Cambodia.

[4] Heckman, J. (1990): "Varieties of Selection Bias", American Economic Review, 80, 331-318.

[5] Heckman, J., Ichimura, H., Todd, P. (1997): "Matching as an Econometric Evaluation Estimator: Evidence from Evaluating a Job Training Program", Review of Economic Studies, 64, 487-535.

[6] Heckman, J., Ichimura, H., Todd, P. (1998): "Matching as an Econometric Evaluation Estimator", Review of Economic Studies, 65, 261-294.

[7] Hirano, K. and Imbens, G. W. (2001): "Estimation of Causal Effects using Propensity Score Weighting: An Application to Data on Right Heart Catheterization", Health Services and Outcomes Research Methodology, 2, 259-278.

[8] Holland, P., (1986): "Statistics and Causal Inference", Journal of the American Statistical Association, 81, 945-970.

[9] Kiernan, B. (1996): "The Pol Pot Regime: Race, Power, and Genocide in Cambodia under the Khmer Rouge, 1975-79", Yale University Press.

[10] Lunceford, J.K., and Davidian, M. (2004): "Stratification and Weighting via the Propensity Score in Estimation of Causal Treatment Effects: A Comparative Study", Statistics in Medicine, 23, 2937-2960.

[11] Marshall, G.N., Schell, T.L., Elliott, M.N., Berthold, S.M. and Chun, C.A. (2005): "Mental Health of Cambodian Refugees 2 Decades After Resettlement in the United States", Journal of American Medical Association, 294, 571-579.

[12] Mollica, R.F., Donelan, K. Tor, S., Lavelle, J., Elias, C. Frankel, M. and Blendon, R.J. (1993): "The Effect of Trauma and Confinement on Functional Health and Mental 
Health Status of Cambodia Living in Thailand-Cambodia Border Camps", Journal of American Medical Association, 270, 581-586.

[13] Mollica, Richard F., Mcinnes, K., Poole, C., and Tor, S. (1998): "Dose-Effect Relationships of Trauma to Symptoms of Depression and Post-Traumatic Stress Disorder among Cambodian Survivors of Mass Violence", British Journal of Psychiatry, 173, 482-488.

[14] Nakagawa, K. (2008): "Gender-Based Violence During the Khmer Rouge Regime Stories of Survivors from the Democratic Kampuchea (1975-1979)", mimeo.

[15] Robins, J.M., and Rotnitzky, A. (1995): "Semiparametric Efficiency in Multivariate Regression Models with Missing Data," Journal of the American Statistical Association, 16, 285-319.

[16] Robins, J.M., and Rotnitzky, A., and Zhao, L.P. (1995): "Analysis of Semiparametric Regression Models for Repeated Outcomes in the Presence of Missing Data," Journal of the American Statistical Association, 90, 106-121.

[17] Rosenbaum, P. and Rubin, D. (1983): "The Central Role of the Propensity Score in Observational Studies for Causal Effects," Biometrika, 70, 41-55.

[18] Rubin, D. (1974): "Estimating Causal Effects on Treatments in Randomized and Non-randomized Studies," Journal of Educational Psychology, 66, 688-701.

[19] Scharfstein D.O., Rotnitzky, A., Robins, J.M. (1999): "Adjusting for Nonignorable Drop-Out Using Semiparametric Nonrespnse Models," with comments and rejoinder, Journal of the American Statistical Association, 94, 1096-1120.

[20] Vannak, H. (2003): "The Khmer Rouge Division 703: From Victory to Selfdestruction," Documentation Center of Cambodia.

[21] Wooldridge, J. M. (2007): "Inverse Probability Weighted Estimation for General Missing Data Problems", Journal of Econometrics, 141, 1281-1301. 
(1a-1) Distribution of Educational Attainment for First Child (Base People)

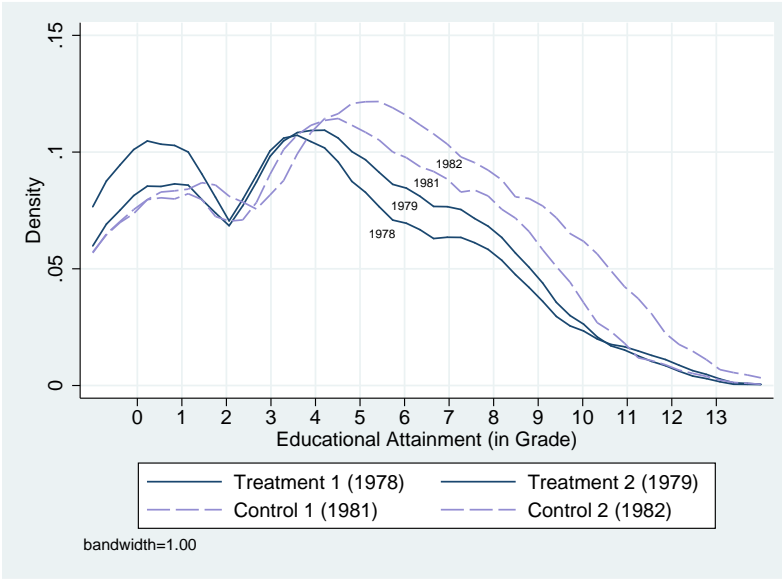

(1a-2) Proportion of Children Aged 6-14 Who Are Currently in School (Base People)

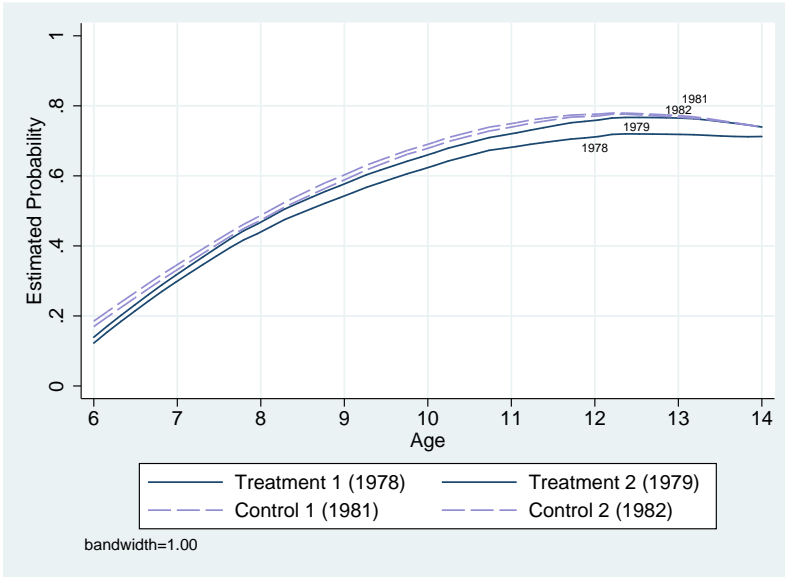

(1a-3) Proportion of Children Aged 6-14 Who Have Never Attended School (Base People)

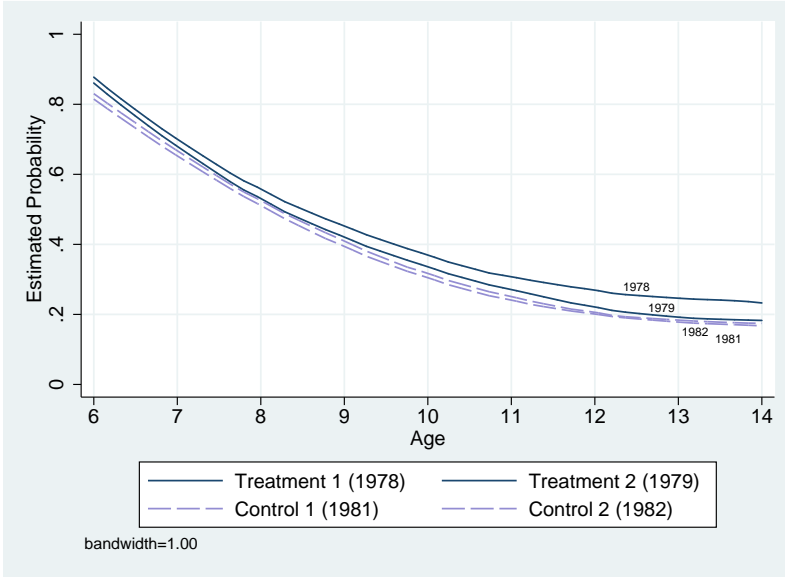

(1b-1) Distribution of Educational Attainment for First Child (New People)

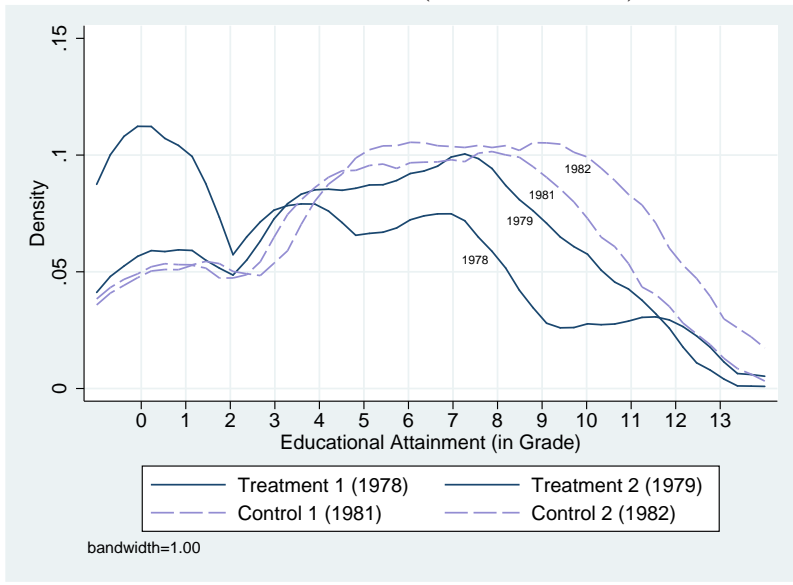

(1b-2) Proportion of Children Aged 6-14 Who Are Currently in School (New People)

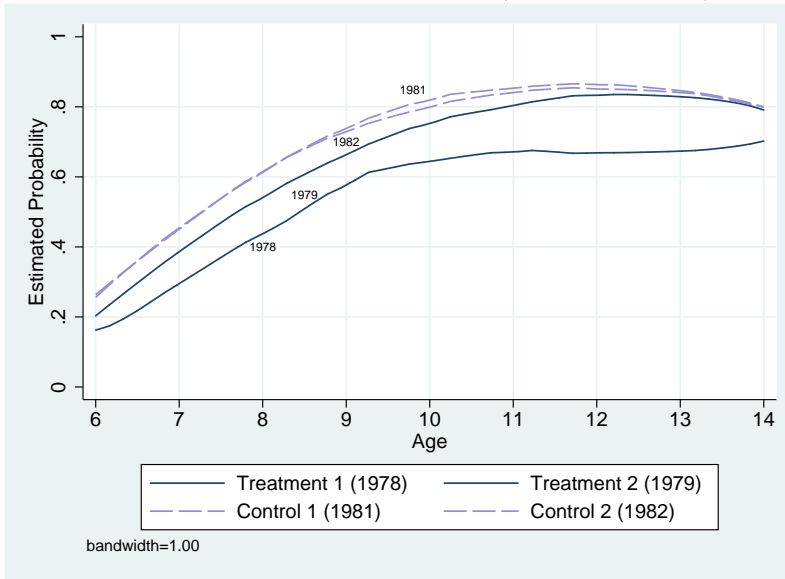

(1b-3) Proportion of Children Aged 6-14 Who Have Never Attended School (New People)

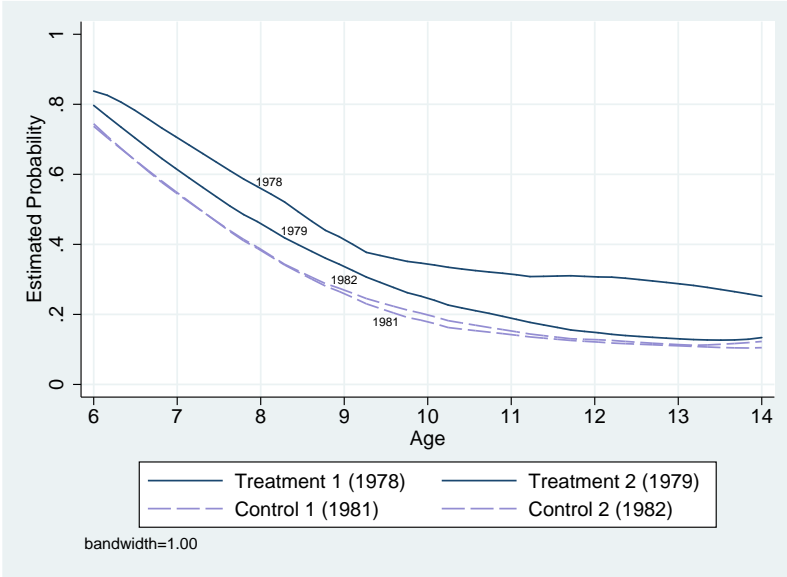

Figure 1: Educational Attainments 

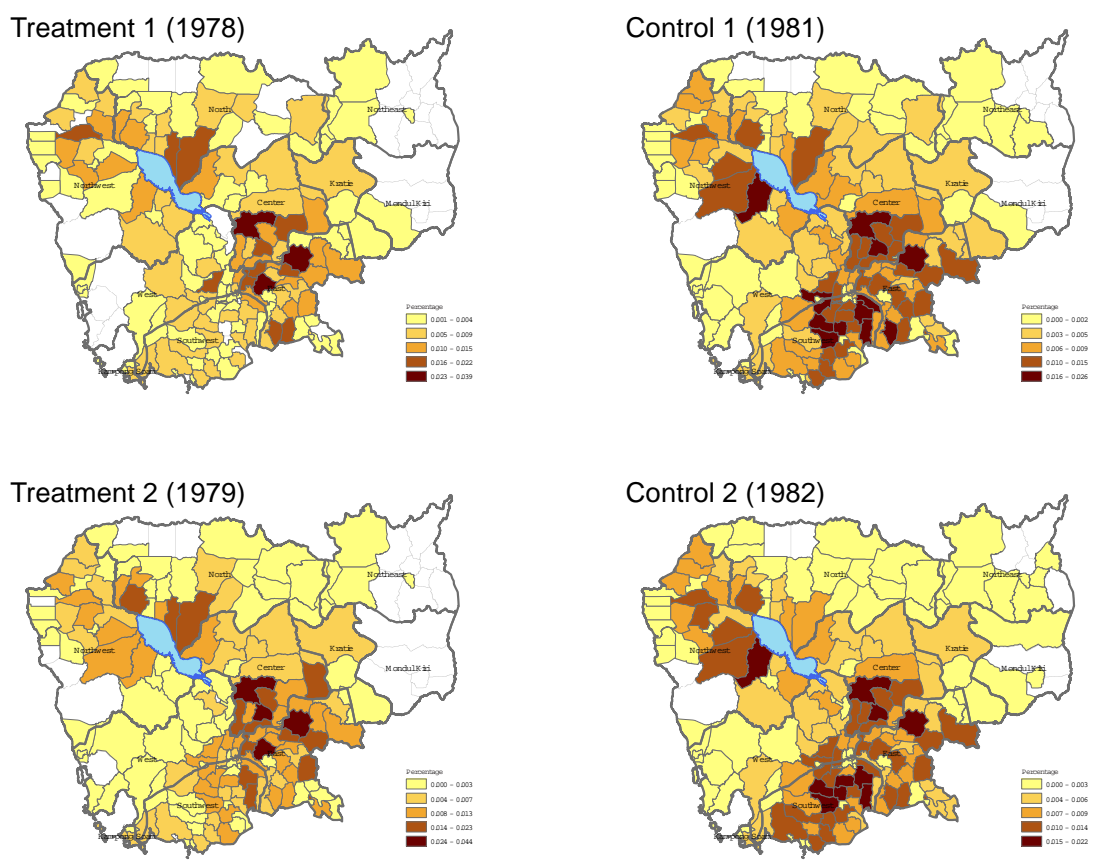

Figure 2: Spatial Distribution of the Samples (Base People)
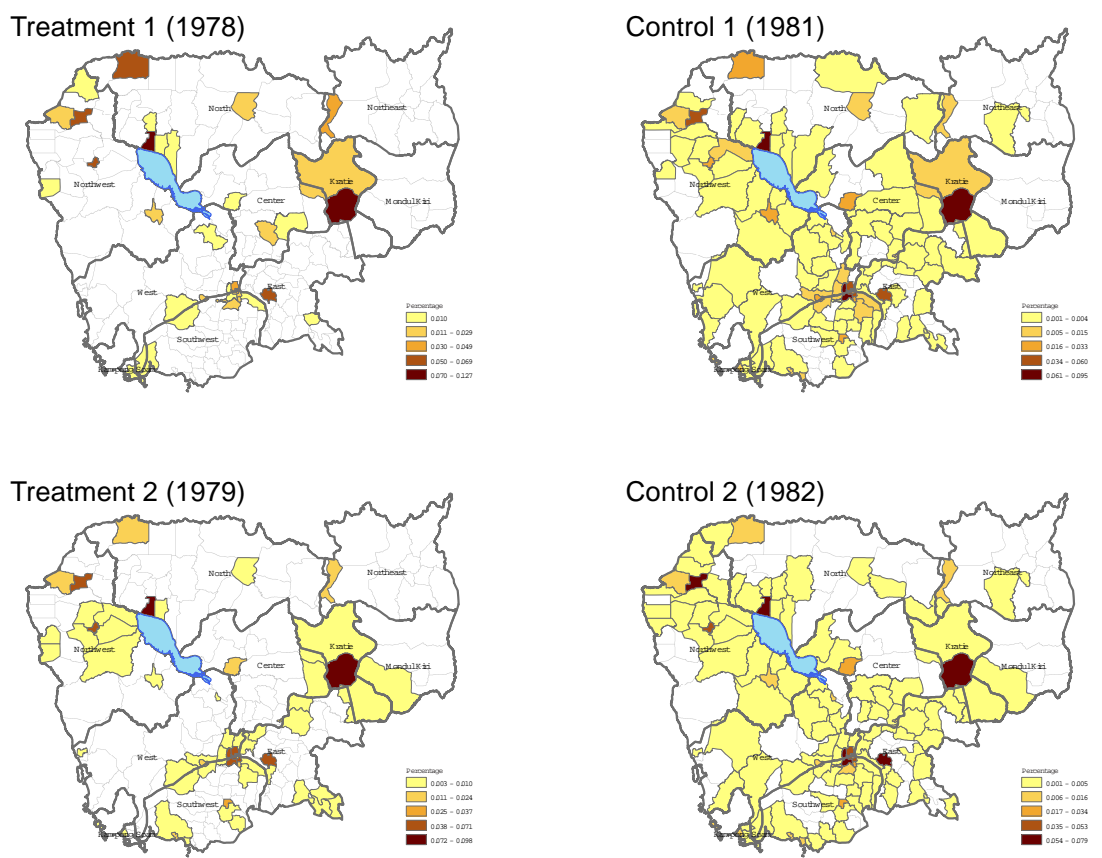

Figure 3: Spatial Distribution of the Samples (New People) 

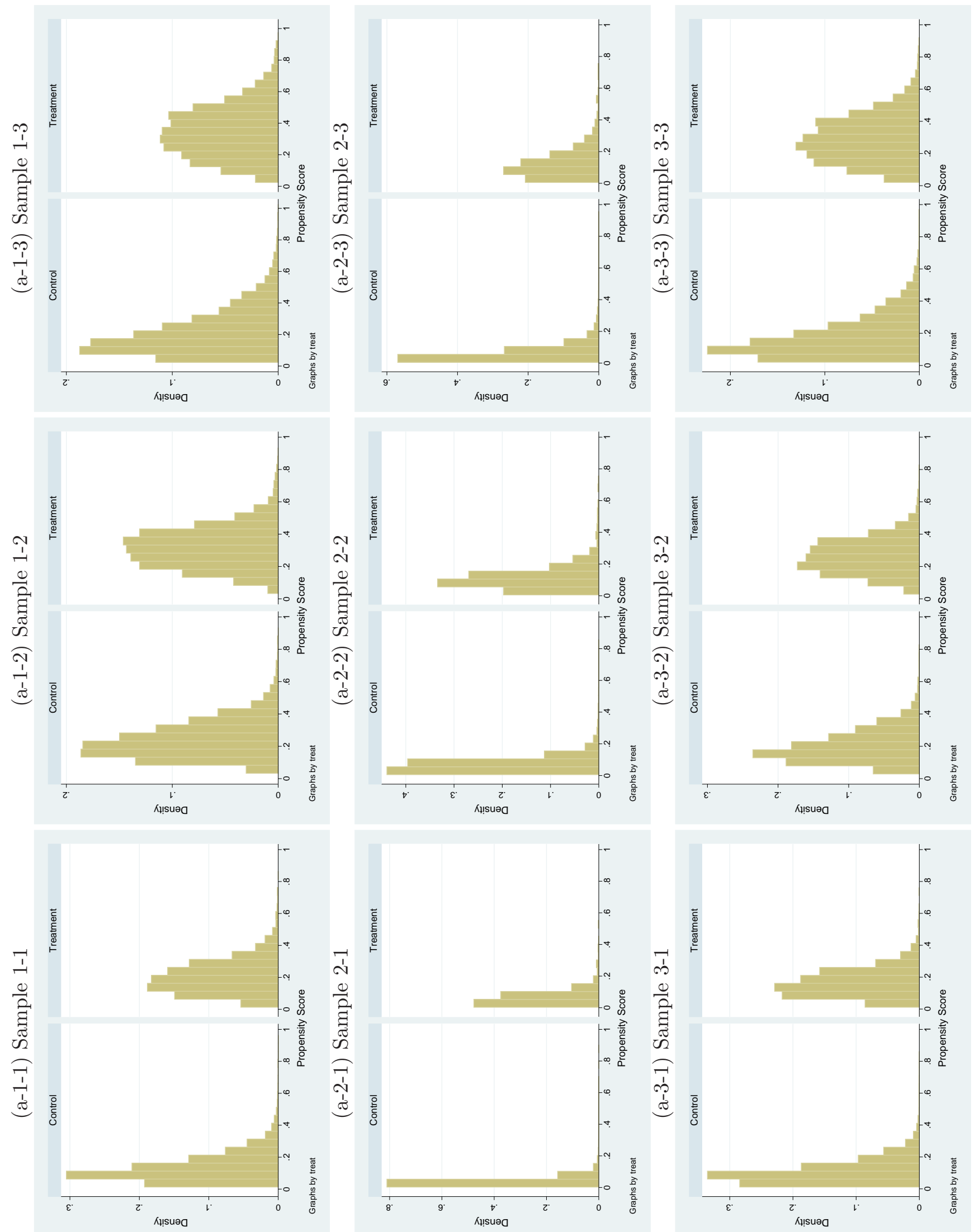

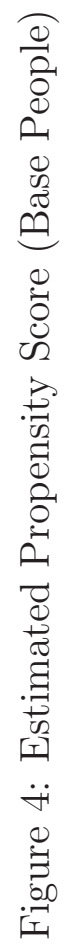



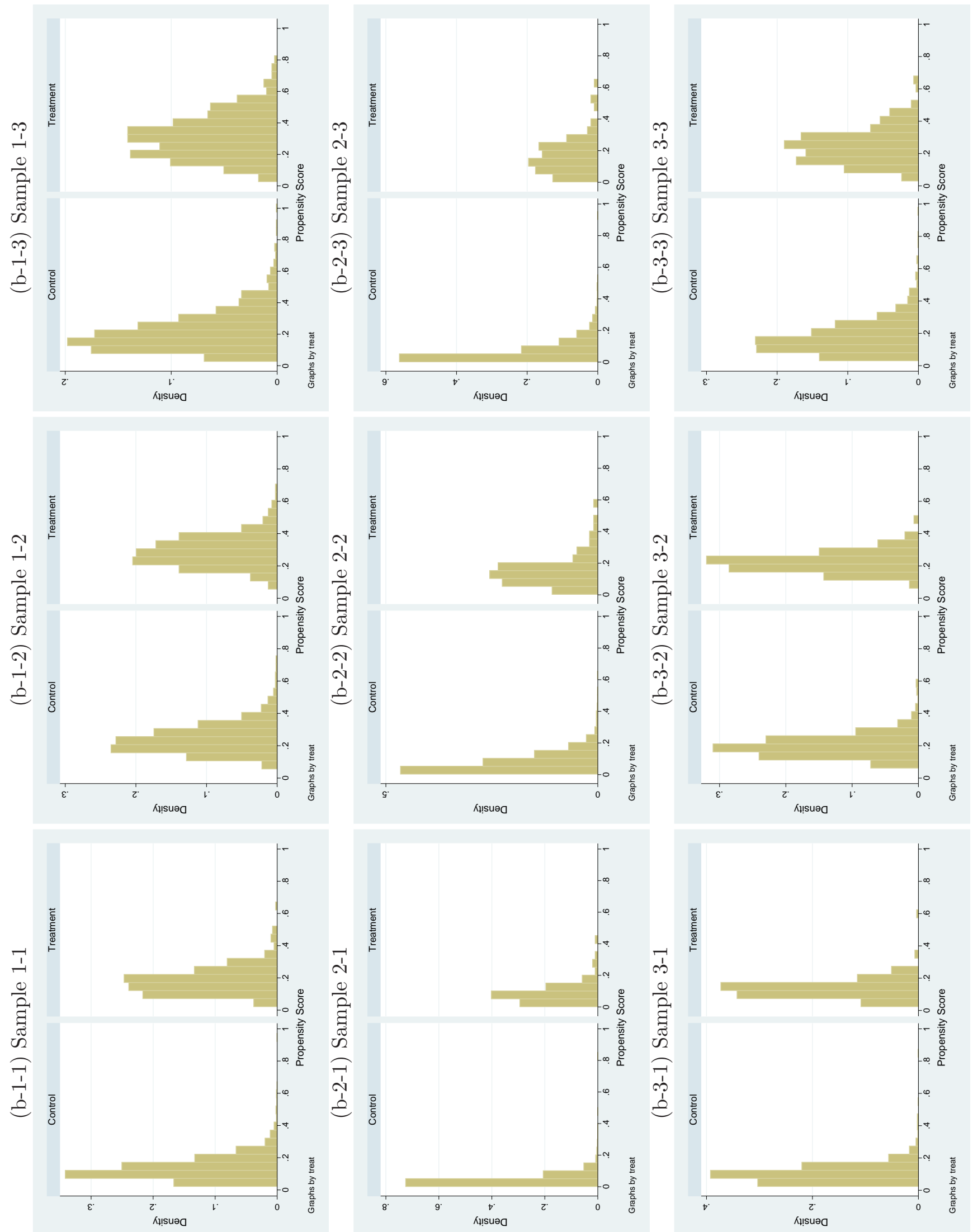

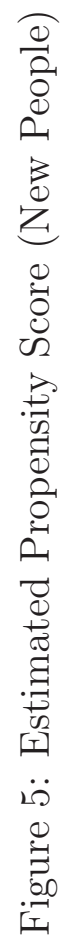


Table 1: Age Table

\begin{tabular}{|c|c|c|c|c|c|c|c|c|c|c|c|c|c|c|}
\hline Year & & & & 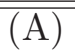 & & & & & & & (B) & & & \\
\hline 1971 & & & & & & & & 6 & 7 & 8 & 9 & 10 & 11 & 12 \\
\hline 1972 & & & & & & & & 7 & 8 & 9 & 10 & 11 & 12 & 13 \\
\hline 1973 & & & & & & & & 8 & 9 & 10 & 11 & 12 & 13 & 14 \\
\hline 1974 & & & & & & & & 9 & 10 & 11 & 12 & 13 & 14 & 15 \\
\hline 1975 & & & & & & & & 10 & 11 & 12 & 13 & 14 & 15 & 16 \\
\hline 1976 & & & & & & & & 11 & 12 & 13 & 14 & 15 & 16 & 17 \\
\hline 1977 & & & & & & & 0 & 12 & 13 & 14 & 15 & 16 & 17 & 18 \\
\hline 1978 & & & & & & 0 & 1 & 13 & 14 & 15 & 16 & 17 & 18 & 19 \\
\hline 1979 & & & & & 0 & 1 & 2 & 14 & 15 & 16 & 17 & 18 & 19 & 20 \\
\hline 1980 & & & & 0 & 1 & 2 & 3 & 15 & 16 & 17 & 18 & 19 & 20 & 21 \\
\hline 1981 & & & 0 & 1 & 2 & 3 & 4 & 16 & 17 & 18 & 19 & 20 & 21 & 22 \\
\hline 1982 & & 0 & 1 & 2 & 3 & 4 & 5 & 17 & 18 & 19 & 20 & 21 & 22 & 23 \\
\hline 1983 & 0 & 1 & 2 & 3 & 4 & 5 & 6 & 18 & 19 & 20 & 21 & 22 & 23 & 24 \\
\hline 1998 & 15 & 16 & 17 & 18 & 19 & 20 & 21 & 33 & 34 & 35 & 36 & 37 & 38 & 39 \\
\hline
\end{tabular}

Note: The table shows ages of children aged 15-21 and women aged 33-39 in 1998 Census data from 1971 to 1983. Panel A shows those for children aged 15-21, while Panel B shows those for women aged 33-39. Note that the Pol Pot regime started in April 1975 and fell in January 1979. 
Table 2: Detailed Procedures for Sampling

\begin{tabular}{ccr}
\hline \hline No. & \multicolumn{1}{c}{ Description of Condition } & Obs. \\
\hline (0) & Total number of households in 1998 Census microdata & $2,188,177$ \\
$(1)$ & A first child in a household as of 1998 is 16 or 17 or 19 or 20 years old. & 351,071
\end{tabular}

Keep the households that satisfy the following conditions.

(2) Household type is "normal" (not "homeless", "boat", "transient").

(3) All members of a household were born in Cambodia.

349,814

(4) All members of a household have never lived outside Cambodia.

340,424

(5) All members of a household speak Khmer as their fist language.

336,872

325,997

(6) All members of a household believe in Buddhism.

323,097

(7) There is mother in a household.

314,878

(8) If a household satisfies with (7), mother's marital status is "married" or "divorced" or "widowed" and that there is father in a household.

291,601

(9) All children in a household have never married.

270,558

(10) Educational attainments of father, mother, and children are neither missing nor "other".

269,661

(11) There are no other/non relatives, grandfather/mother/child in a household. 214,700

(12) If age of $i^{\text {th }}$ child is same as that of $i+1^{\text {th }}$ child, birth place of $i^{\text {th }}$ child is same as that of $i+1^{\text {th }}$ child.

214,595

(13) Number of mother's own children alive is equal to that of children living together in 1998.

120,050

9,671

(14-1) Mother's birth place is a provincial town or Phnom Penh. (New people)

(14-2) Mother's birth place is neither a provincial town nor Phnom Penh and the birth place of a first child is same as that of mother. (Base people)

Treatment Groups

(15-1) Households with mother aged 34-38 and a first child aged 20 (Treatment 1). 1,230

(15-1) Households with mother aged 34-38 and a first child aged 19 (Treatment 2). 3,993

Control Groups

(15-2) Households with mother aged 34-38 and a first child aged 17 (Control 1). 14,661

(15-2) Households with mother aged 34-38 and a first child aged 16 (Control 2). 15,761

30,422

Samples

Sample 1-1: Treatment 1 and 2; Control 1 and 2 (base: 32,626; new: 3,019)

35,645

Sample 1-2: Treatment 1 and 2; Control 1

(base: 18,194; new: 1,690)

19,884

Sample 1-3: Treatment 1 and 2; Control 2

(base: 19,213; new: 1,771)

20,984

Sample 2-1: Treatment 1; Control 1 and 2

(base: 28,957 ; new: 2,695 )

31,652

(base: 14,525; new: 1,366)

15,891

Sample 2-3: Treatment 1; Control 2

(base: 15,544; new: 1,447)

16,991

Sample 3-1: Treatment 2; Control 1 and 2

(base: 31,514 ; new: 2,901)

34,415

Sample 3-2: Treatment 2; Control 1

(base: 17,082; new: 1,572)

18,654

Sample 3-3: Treatment 2; Control 2

(base: 18,101; new: 1,653)

19,754

Note: The table shows detailed results of sampling. While 2,188,662 households were contained in an original data set, all the duplicated households, except one of them, were excluded. 2,188,177 households were used for sampling and fifteen conditions were imposed to develop six samples for this study. 
Table 3: Mother's Marital Status

\begin{tabular}{lcccc}
\hline \hline & Treatment 1 & \multicolumn{4}{c}{ Treatment 2 } & Control 1 & Control 2 \\
\hline Married & 0.907 & 0.914 & 0.918 & 0.917 \\
Divorced & 0.030 & 0.029 & 0.034 & 0.033 \\
Widowed & 0.063 & 0.058 & 0.049 & 0.050 \\
Observations & 1,112 & 3,669 & 13,413 & 14,432 \\
\hline & 0.864 & (B) New People \\
Married & 0.911 & 0.923 & 0.939 \\
Divorced & 0.034 & 0.031 & 0.030 & 0.027 \\
Widowed & 0.102 & 0.059 & 0.047 & 0.034 \\
Observations & 118 & 324 & 1,248 & 1,329 \\
\hline
\end{tabular}

Note: The table shows the proportion of married, divorced, and widowed households by different groups and samples. 


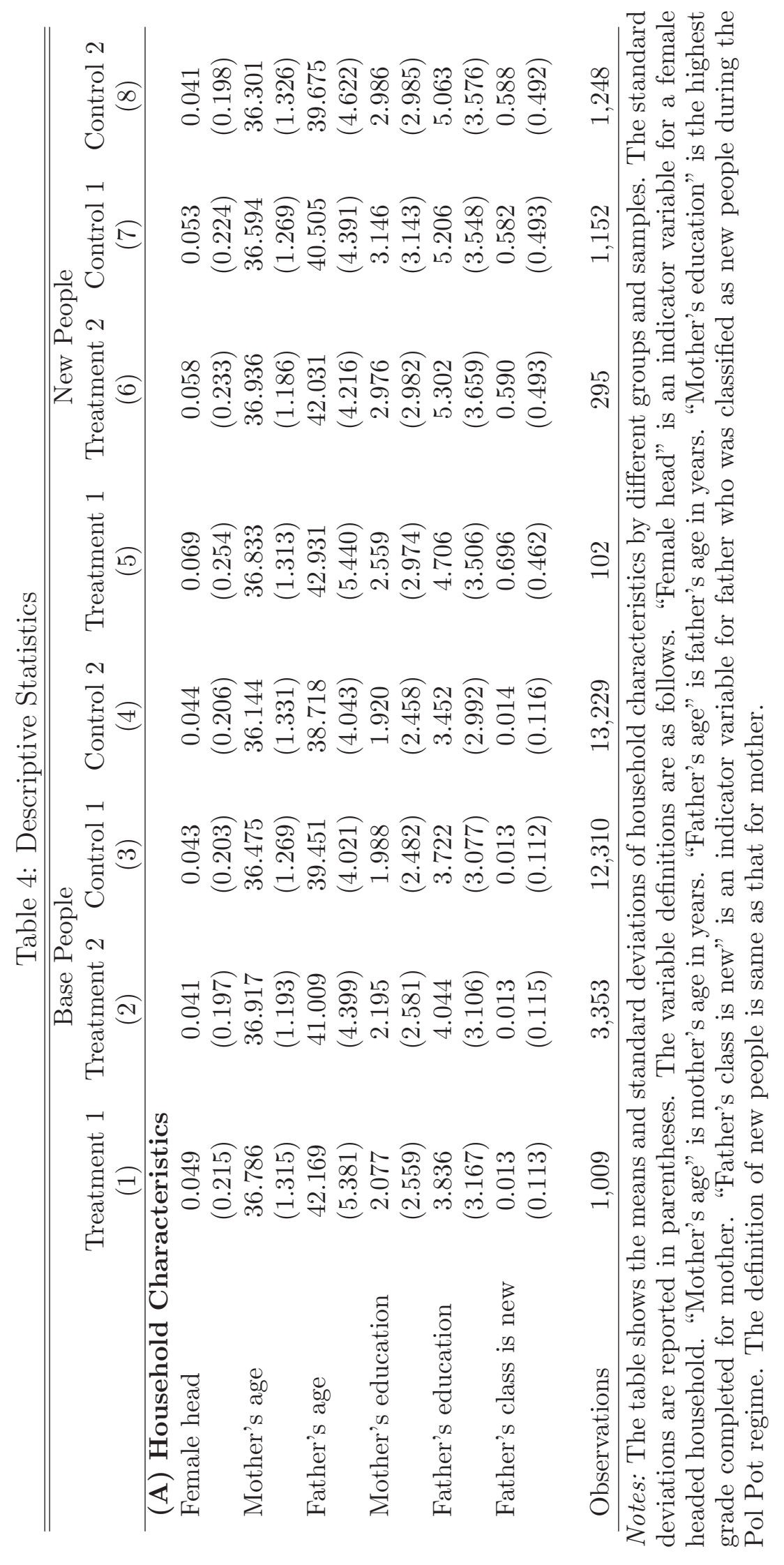




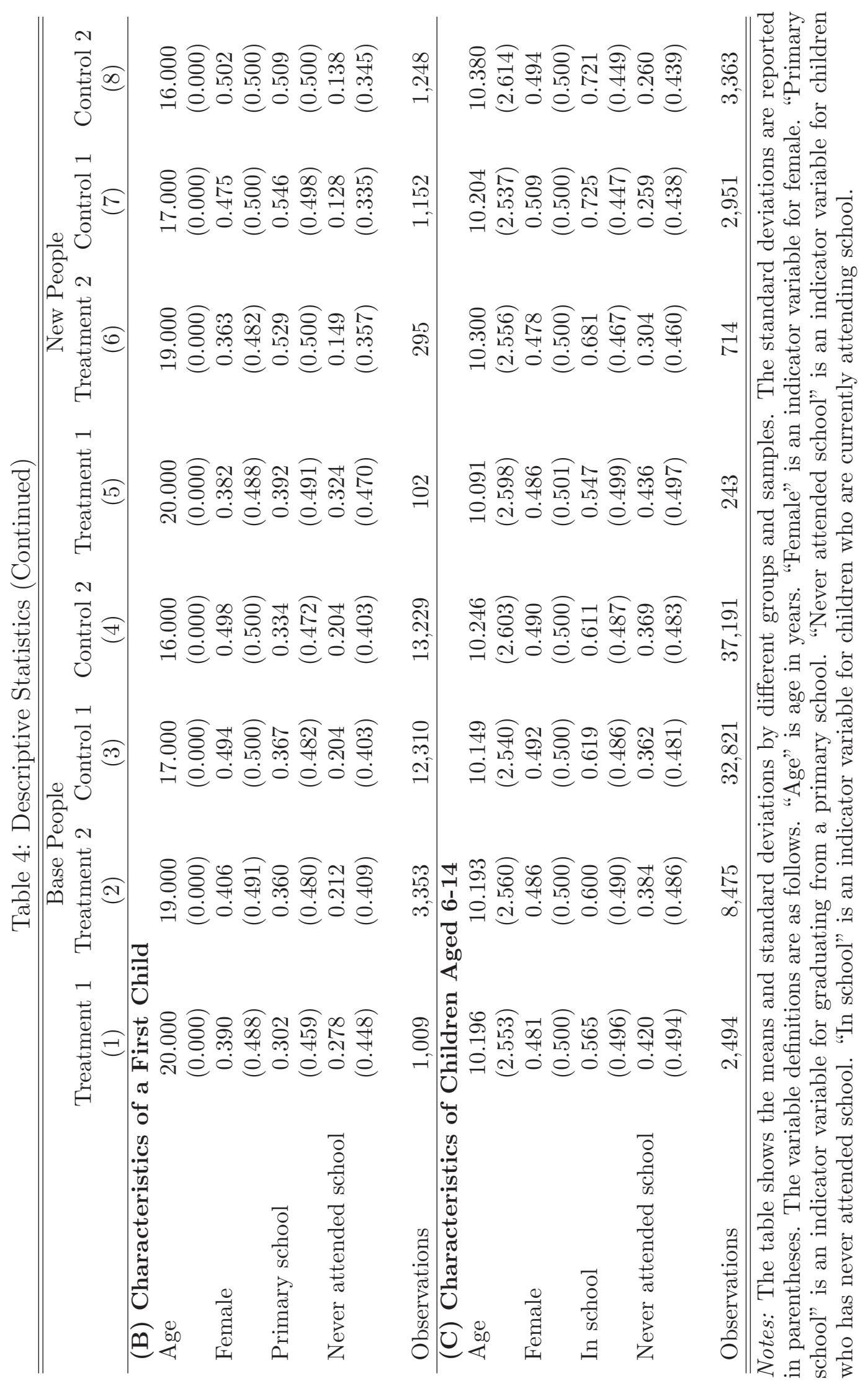




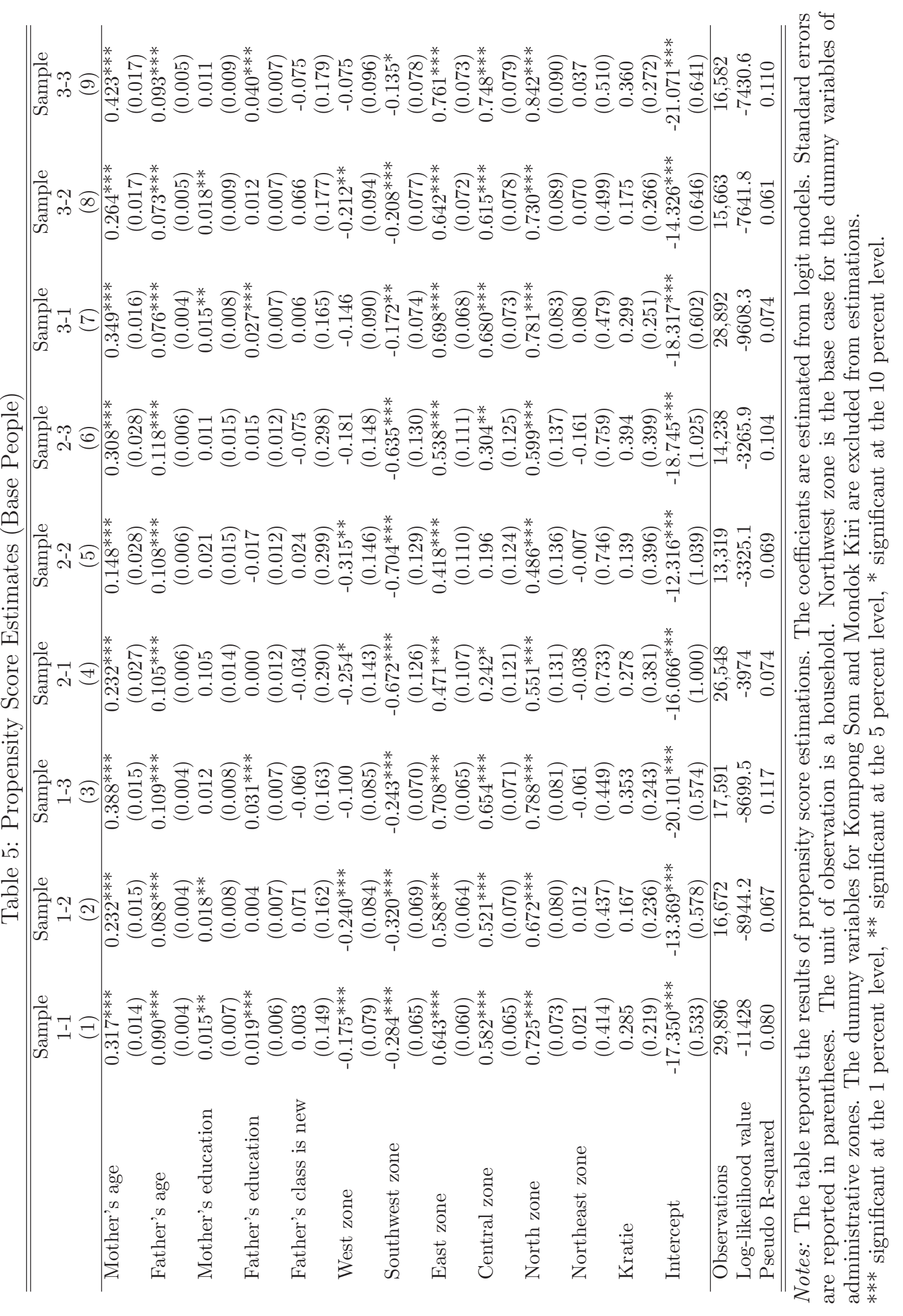




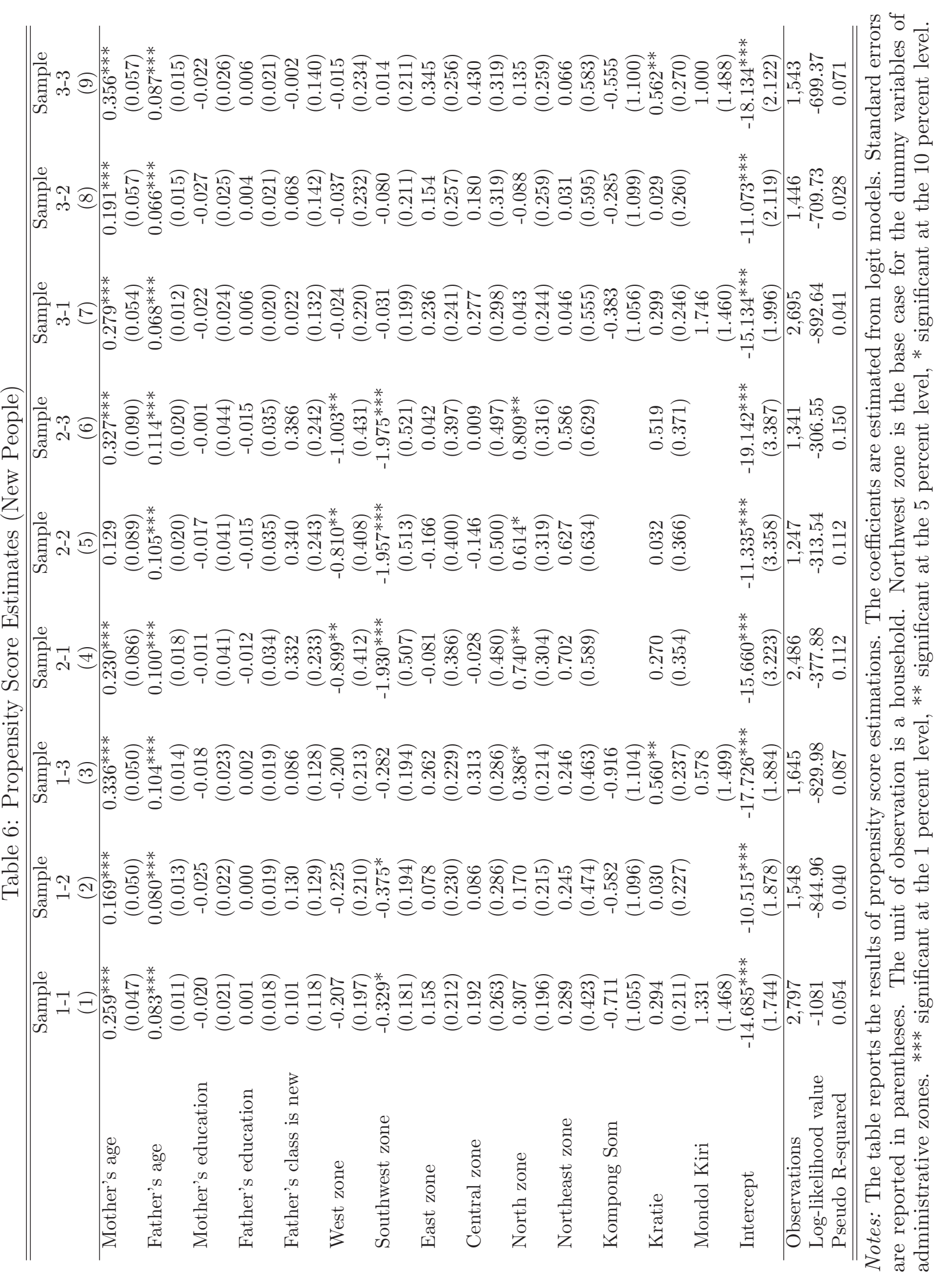




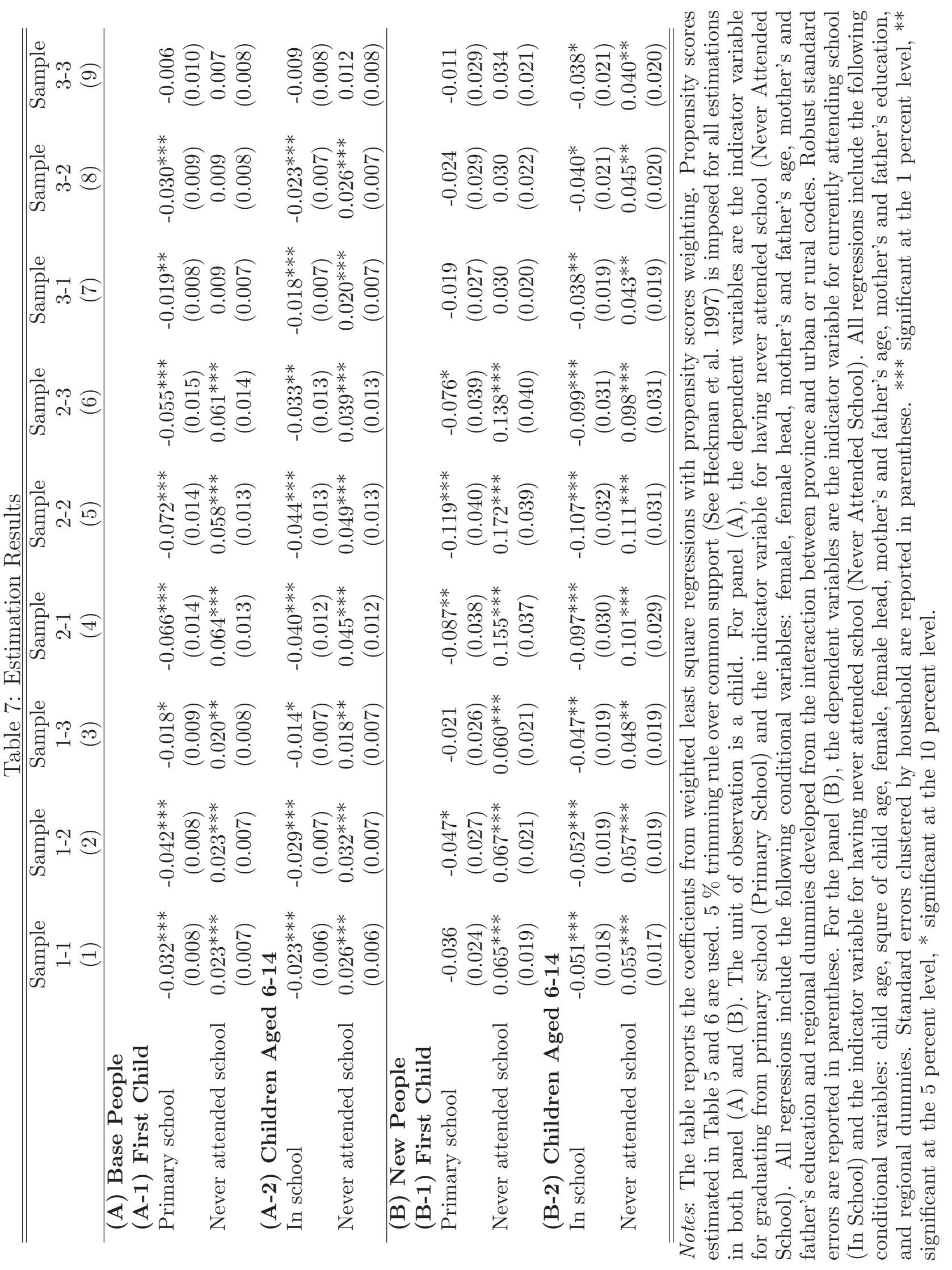




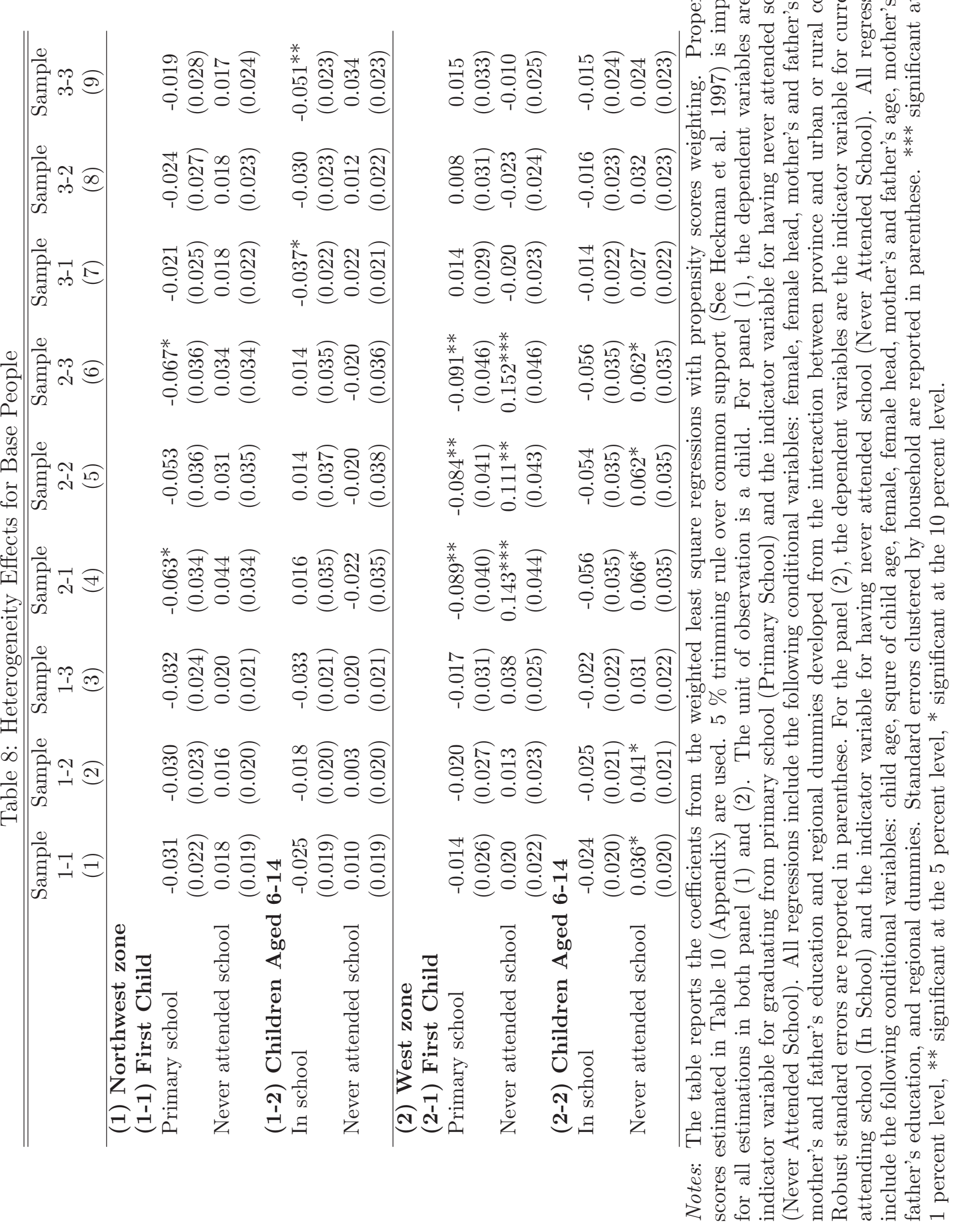




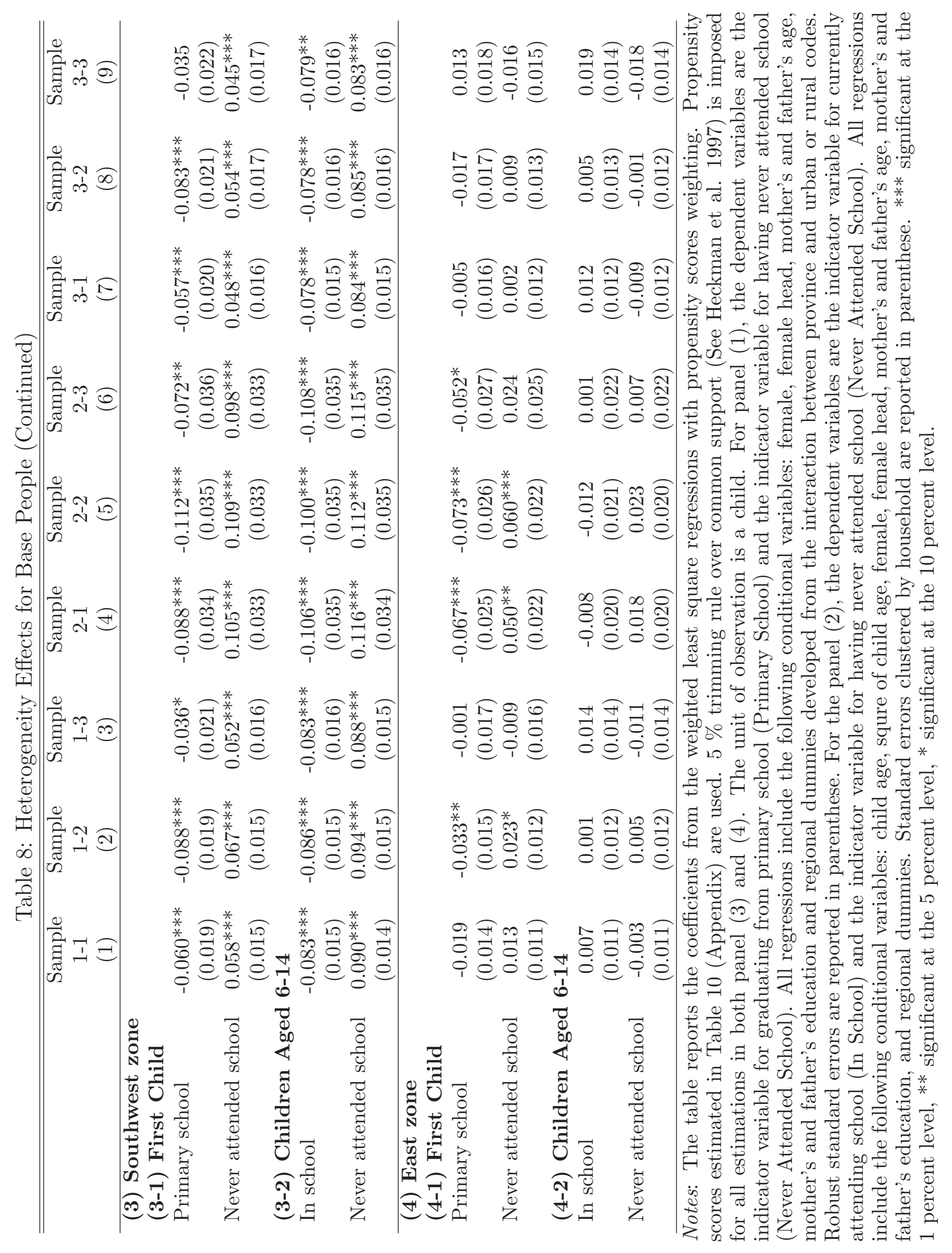




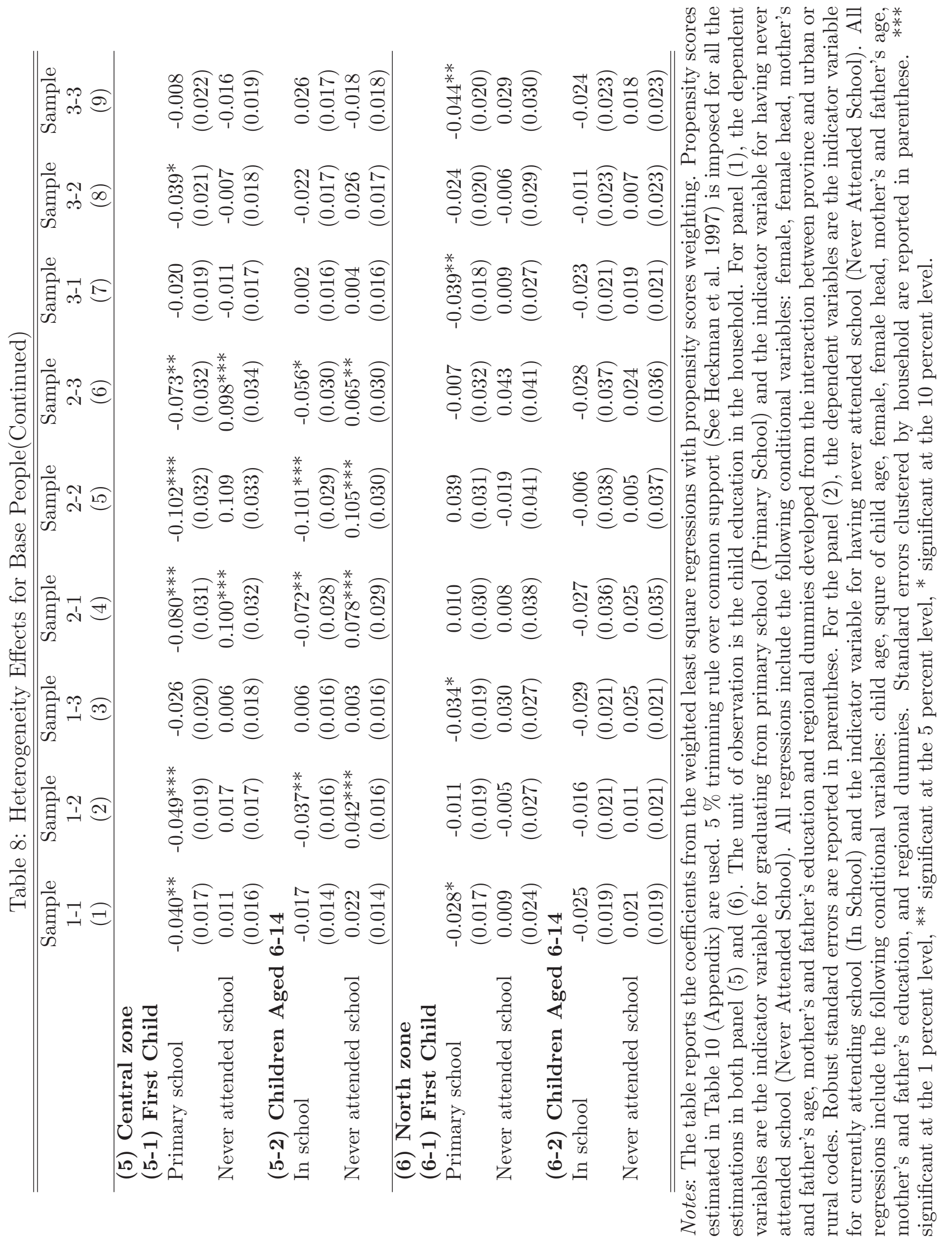




\section{Appendix}

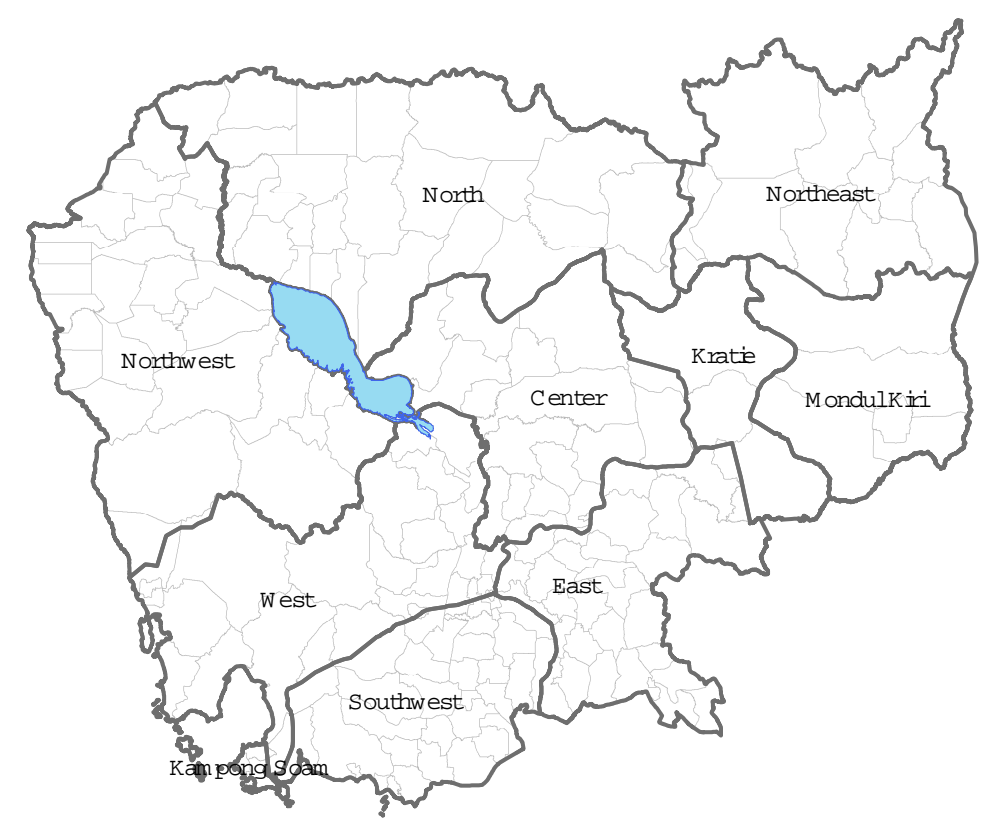

Figure 6: Administrative Zone under the Khmer Rouge Regime

The figure shows the Democratic Kampuchea (DK) zone in 1977. This map was developed by the author with ArcGIS based on the degital layer provided by the website of Cambodian Genocide Program at Yale university (http://www.yale.edu/cgp/). Census microdata did not record the information based on this DK zone. To match the present district codes with the DK zone, we first calculated the center of each district with ArcGIS. We then matched these centers with DK zones. 
Table 9: Definition of Variables

\begin{tabular}{|c|c|}
\hline Variable & Definition \\
\hline \multicolumn{2}{|c|}{ A. Dependent Variables } \\
\hline Primary School & $\begin{array}{l}1 \text { if a first child in a household has graduated from a primary school, } \\
0 \text { otherwise }\end{array}$ \\
\hline Never attended school & $\begin{array}{l}1 \text { if a first child/ children aged 6-14 in a household has/have never } \\
\text { attended school, } 0 \text { otherwise }\end{array}$ \\
\hline In school & $\begin{array}{l}1 \text { if a child aged } 6 \text { - } 14 \text { in a household attends a school at the time of } \\
1998 \text { census, } 0 \text { otherwise }\end{array}$ \\
\hline \multicolumn{2}{|c|}{ B. Independent Variables } \\
\hline Female head & 1 if female is head of a household, 0 otherwise \\
\hline Mother's age & The number of mother's age at the time of 1998 Census \\
\hline Father's age & The number of father's age at the time of 1998 Census \\
\hline Mother's education & The number of a highest grade completed for mother \\
\hline Father's education & The number of a highest grade completed for father \\
\hline Father is new people & $\begin{array}{l}1 \text { if father was classified as new people in the Pol Pot regime, } \\
0 \text { otherwise The definition of new people is as follows. } \\
\text { Father is defined as new people if his birth place was a provincial } \\
\text { town or Phnom Penh. }\end{array}$ \\
\hline Age & The number of child age at the time of 1998 Census \\
\hline Female & 1 if a child is female, 0 otherwise \\
\hline Northwest zone & 1 if a household has a first child born in Northwest zone, 0 otherwise \\
\hline West zone & 1 if a household has a first child born in West zone, 0 otherwise \\
\hline Southwest zone & 1 if a household has a first child born in Southwest zone, 0 otherwise \\
\hline East zone & 1 if a household has a first child born in East zone, 0 otherwise \\
\hline Central zone & 1 if a household has a first child born in Central zone, 0 otherwise \\
\hline North zone & 1 if a household has a first child born in North zone, 0 otherwise \\
\hline Northeast zone & 1 if a household has a first child born in Northeast zone, 0 otherwise \\
\hline Kompong Som & 1 if a household has a first child born in Kompong Som, 0 otherwise \\
\hline Kratie & 1 if a household has a first child born in Kratie, 0 otherwise \\
\hline Mondol Kiri & 1 if a household has a first child born in Mondol Kiri, 0 otherwise \\
\hline Regional dummies & Indicator variables of interactions between province and urban/ rural \\
\hline \multicolumn{2}{|l|}{ C. Other Variables } \\
\hline Married & $\begin{array}{l}1 \text { if mother's marital status is "married" at the time of } 1998 \text { Census, } \\
0 \text { otherwise }\end{array}$ \\
\hline Divorced: & $\begin{array}{l}1 \text { if mother's marital status is "divorced" at the time of } 1998 \text { Census, } \\
0 \text { otherwise }\end{array}$ \\
\hline Widowed: & $\begin{array}{l}1 \text { if mother's marital status is "widowed" at the time of } 1998 \text { Census, } \\
0 \text { otherwise }\end{array}$ \\
\hline
\end{tabular}




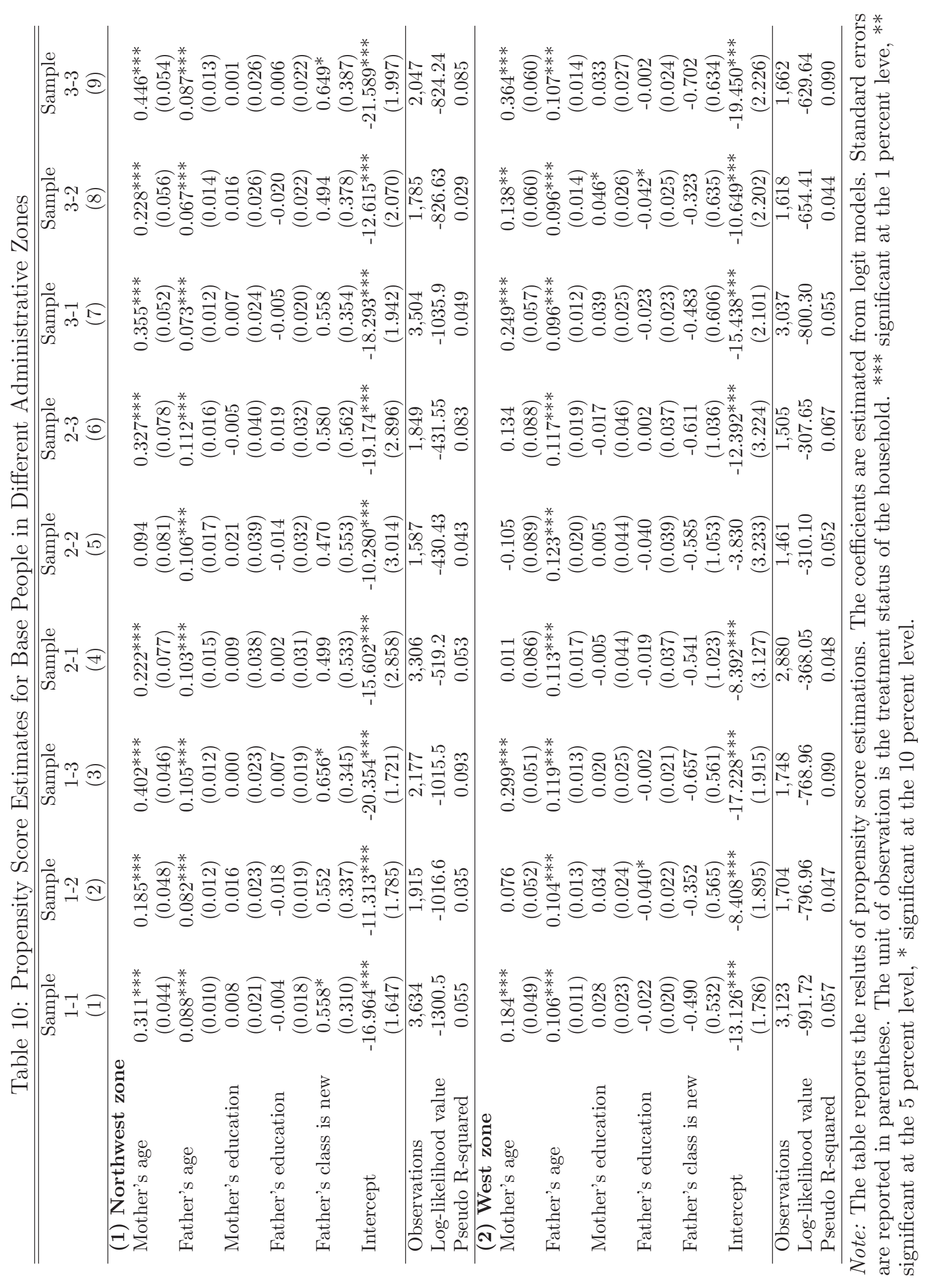




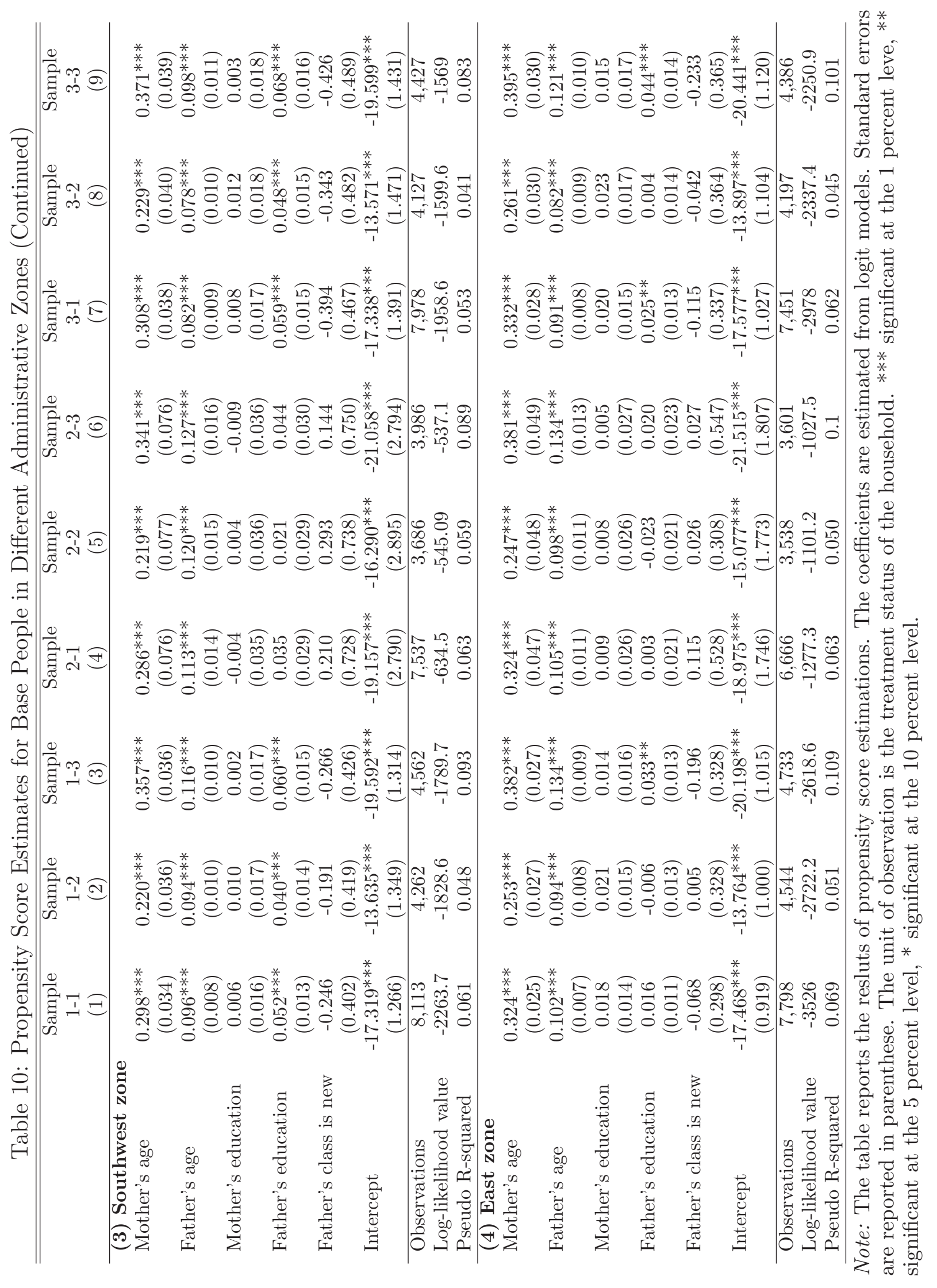




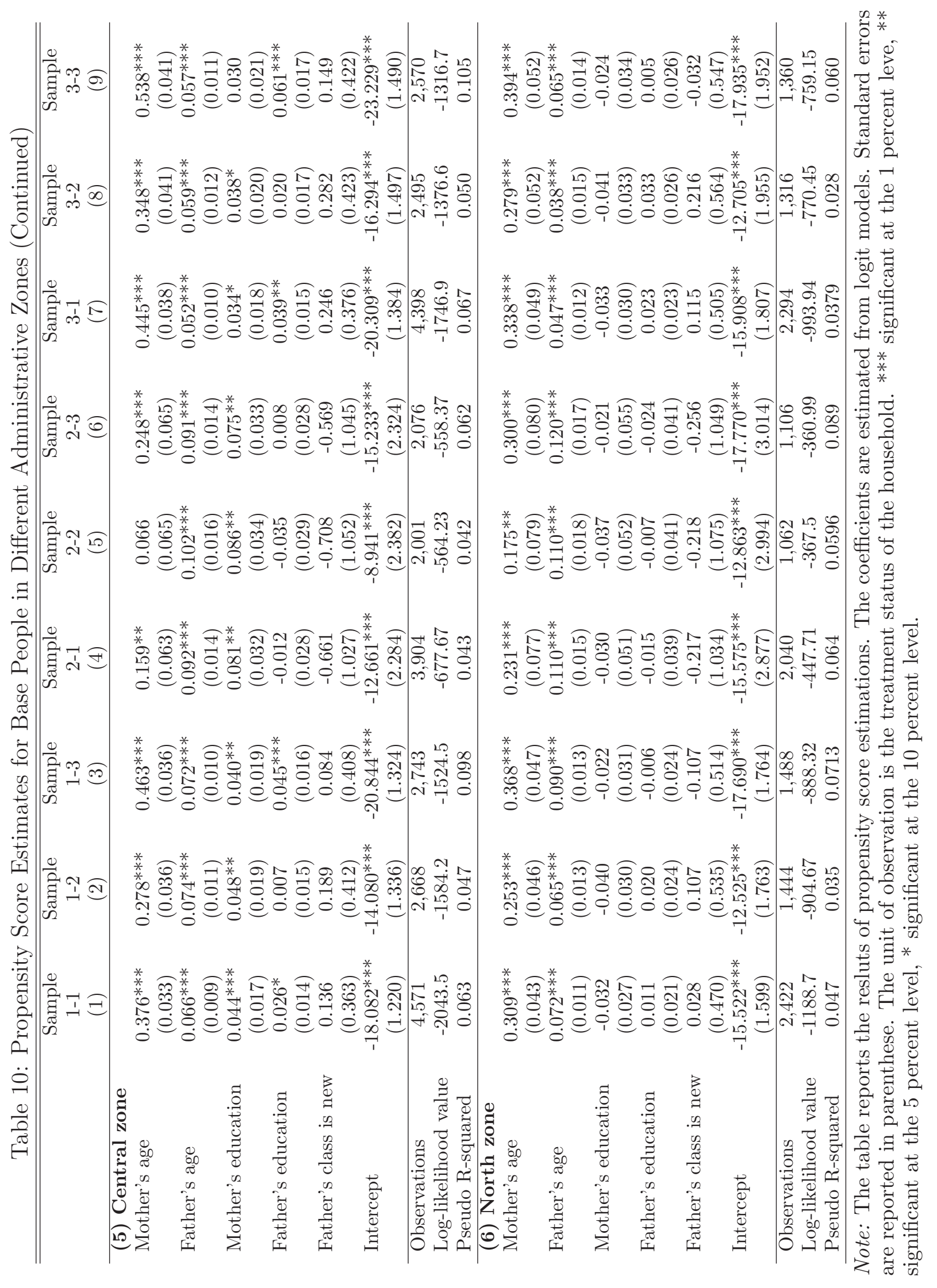

